\title{
Drugs and Targets in Fibrosis
}

\author{
Xiaoyi $\mathrm{Li}^{1}$, Lixin Zhu ${ }^{2,3 *}$, Beibei Wang ${ }^{1}$, Meifei Yuan ${ }^{4}$ and Ruixin Zhu ${ }^{1 *}$ \\ 1 Department of Gastroenterology, School of Life Sciences and Technology, Shanghai East Hospital, Tongji University, \\ Shanghai, China, ${ }^{2}$ Department of Pediatrics, Digestive Diseases and Nutrition Center, State University of New York at Buffalo, \\ Buffalo, NY, United States, ${ }^{3}$ Genome, Environment and Microbiome Community of Excellence, State University of New York \\ at Buffalo, Buffalo, NY, United States, ${ }^{4}$ Center for Drug Discovery, SINO High Goal Chemical Technology Co., Ltd., Shanghai, \\ China
}

OPEN ACCESS

Edited by:

Jinyong Peng,

Dalian Medical University, China

Reviewed by:

Xufeng Tao',

Dalian Medical University, China Ramin Massoumi,

Lund University, Sweden

*Correspondence:

Lixin Zhu

lixinzhu@buffalo.edu

Ruixin Zhu

rxzhu@tongji.edu.cn

Specialty section:

This article was submitted to

Gastrointestinal and Hepatic

Pharmacology,

a section of the journal

Frontiers in Pharmacology

Received: 28 August 2017 Accepted: 08 November 2017 Published: 23 November 2017

Citation:

Li X, Zhu L, Wang B, Yuan M and Zhu R (2017) Drugs and Targets in Fibrosis. Front. Pharmacol. 8:855. doi: 10.3389/fphar.2017.00855
Fibrosis contributes to the development of many diseases and many target molecules are involved in fibrosis. Currently, the majority of fibrosis treatment strategies are limited to specific diseases or organs. However, accumulating evidence demonstrates great similarities among fibroproliferative diseases, and more and more drugs are proved to be effective anti-fibrotic therapies across different diseases and organs. Here we comprehensively review the current knowledge on the pathological mechanisms of fibrosis, and divide factors mediating fibrosis progression into extracellular and intracellular groups. Furthermore, we systematically summarize both single and multiple component drugs that target fibrosis. Future directions of fibrosis drug discovery are also proposed.

Keywords: fibrosis, drug, target, pathological mechanism, pharmacology

\section{INTRODUCTION}

Fibrosis, characterized by excess accumulation of extracellular matrix (ECM), is a common pathological process in many chronic diseases or injuries. Many irritations trigger the pro-fibrotic responses, including persistent infections, radiation, chemical agents, genetic disorders, and autoimmune diseases. The development of fibrosis is accompanied by the loss of a fraction of resident cells and their replacement by ECM, which would finally lead to tissue remodeling and organ failure. Fibrosis contributes to high morbidity and mortality in many diseases such as dilated cardiomyopathy and idiopathic pulmonary fibrosis (IPF) (Gulati et al., 2013; Hutchinson et al., 2015), and inevitably causes a prominent global clinical burden (Raimundo et al., 2016). For example, a study of medicare population aged 65 years and older showed that the incidence of IPF was around 93.7 cases per 100,000 person-years while the cumulative prevalence increased steadily to 494.5 cases per 100,000 person-years across 2001 to 2011 in US (Raghu et al., 2014). Besides, the mortality of non-alcoholic fatty liver disease (NAFLD) patients with a high probability of fibrosis was $69 \%$ higher than those without fibrosis (Kim et al., 2013).

As a long-lasting pathological phenomenon, fibrosis occurs in various tissues and organs (Figure 1), more often in heart, lung, kidney, liver, skin (Rockey et al., 2015), and less frequently in other tissues and organs such as pancreas, intestine, eye (Wynn, 2008), nerve system (Kawano et al., 2012), mediastinum (Parish and Rosenow, 2002), retroperitoneum (Caiafa et al., 2013), joint and tendon (arthrofibrosis).

Fibrosis contributes to the development of many diseases. First, many studies have demonstrated that the core mechanisms in fibrosis across various tissues and organs are similar. Wang and colleagues found that the interaction between transforming growth factor- $\beta$ (TGF- $\beta$ ) and connective tissue growth factor signaling is required in kidney, liver, and lung fibrosis (Wang Q. et al., 2011). Makarev and colleagues identified a number of common pathways between lung 


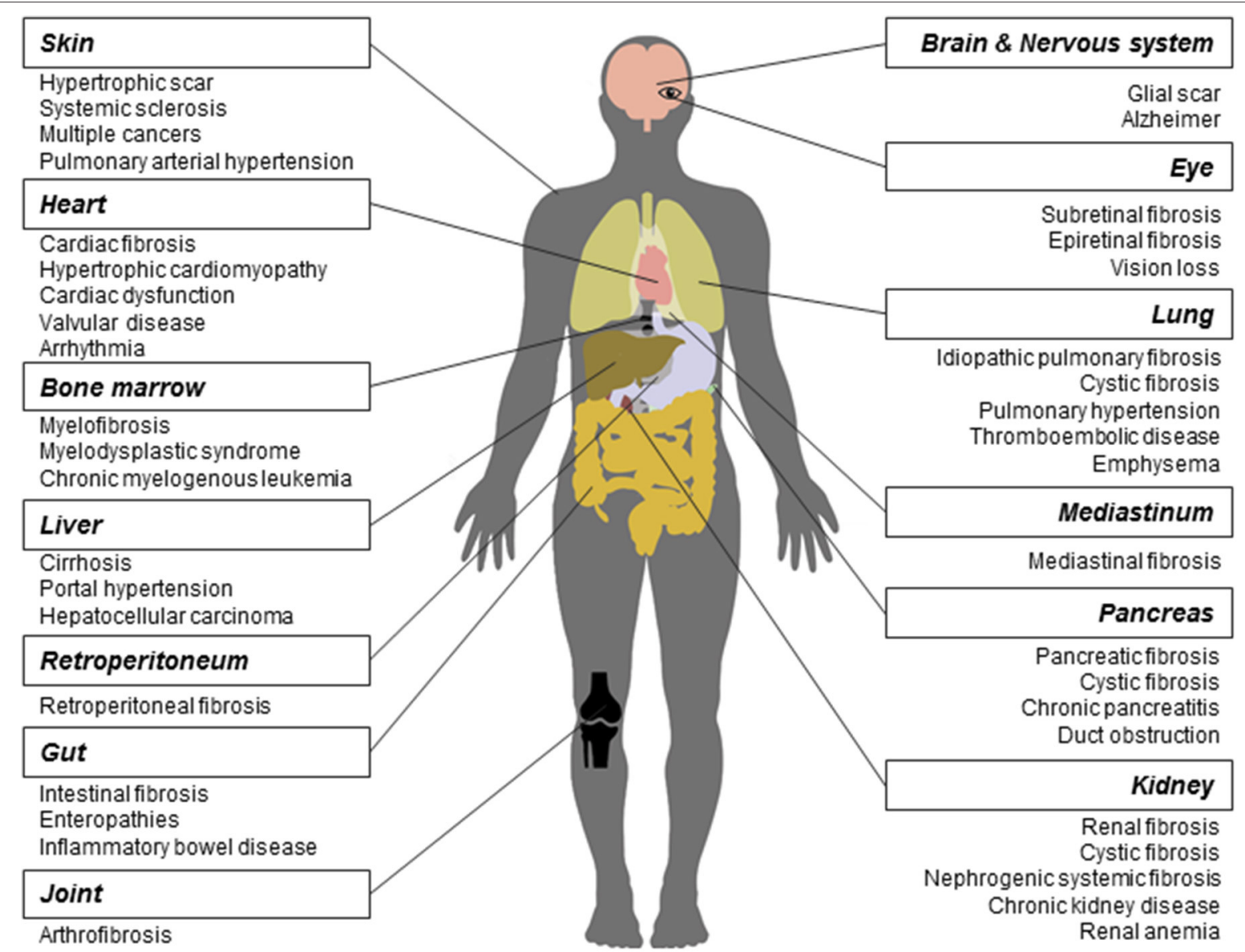

FIGURE 1 | Fibrosis and related diseases in various tissues and organs. Fibrosis is a pathological process that could occur in many tissues and organs and is associated with multiple diseases. Commonly reported fibrosis and associated diseases are listed.

and liver fibrogenesis, such as TGF- $\beta$, interleukin-6(IL-6), and integrin-linked kinase signaling (Makarev et al., 2016). Moreover, Wenzke and colleagues detected 90 genes, as well as several networks associated with connective tissue disorders, that play important roles in multi-organ fibrosis including lung, heart, liver, and kidney (Wenzke et al., 2012). On the basis of common pathogenesis across fibroproliferative diseases, some new drugs were proved effective in the treatment of fibrosis across different tissues and organs. For example, Pirfenidone has entered into

Abbreviations: ECM, extracellular matrix; IPF, idiopathic pulmonary fibrosis; NAFLD, non-alcoholic fatty liver disease; TGF- $\beta$, transforming growth factor$\beta$; IL-6, interleukin-6; SSc, systemic sclerosis; PDGF, platelet derived growth factor; EMT, epithelial-mesenchymal transition; HSC, hepatic stellate cell; MMPs, matrix metalloproteinases; $\alpha$-SMA, $\alpha$-smooth muscle actin; HGF, hepatocyte growth factor; TNF, tumor necrosis factor; STAT3, signal transducer and activator of transcription 3; TIMPs, tissue inhibitor of metalloproteinases; Hh signaling, hedgehog signaling; mTOR, mechanistic target of rapamycin, MAPK, mitogenactivated protein kinase; PPAR- $\gamma$, peroxisome proliferator activated receptor $\gamma$; FXR, farnesoid-X receptor; LOXL2, lysyl oxidase homolog 2; ROS, reactive oxygen species; CKD, chronic kidney disease; ET, endothelin; BMPER, BMP endothelial cell precursor-derived regulator; TCM, traditional Chinese medicines; FZHY, Fuzhenghuayu capsule; NFкB, nuclear factor kappa-light-chain-enhancer of activated B cells; QSYQ, Qishenyiqi; QHD, Qushi Huayu Decoction. cryo-EM, cryo-electron microscopy. the phase II clinical trial for treating the systemic sclerosis(SSc) (Khanna et al., 2016) and the phase III for IPF (King et al., 2014), respectively. Interferon drug Actimmune has been evaluated in patients with IPF (Skaria et al., 2015), liver (Muir et al., 2006), and cystic fibrosis (Moss et al., 2005).

Second, in different tissues and organs, multiple fibrotic diseases are related to each other. They are usually triggered by the same irritation and occur simultaneously. For example, heart and kidney together develop fibrosis (cardiorenal fibrosis) owing to the imbalance of natriuretic peptide system pathway and renin angiotensin aldosterone system/TGF- $\beta 1$ pathway in aging (Sangaralingham et al., 2016). Chronic or acute renal failure may induce nephrogenic systemic fibrosis developed from thickening skin (Reiter et al., 2012) to impaired internal organs. In addition, cystic fibrosis, caused by gene mutation, could widely affect multiple organs, such as lung, kidney, and pancreas. Moreover, fibrosis is frequently a common pathological process in NAFLD and inflammatory bowel disease. Replacement of heart tissues by fibrotic protein could alter the ventricle size and shape, leading to hypertrophic cardiomyopathy (Khan and Sheppard, 2006). Cancers such as hepatocellular carcinoma share a series of risk factors with liver fibrosis (De Minicis et al., 2012). 
Here we review the current knowledge on the pathological mechanisms of fibrosis and systematically summarize drugs targeting fibrosis in different fibroproliferative diseases. Future directions for fibrosis drug discovery are also proposed.

\section{PATHOGENESIS OF FIBROSIS}

Fibrosis is considered as pathological outcomes of normal wound healing (Figure 2). When injuries occur and epithelial and/or endothelial cells are damaged, pro-inflammatory cytokines are released by the coagulation cascade for immune cell recruitment, mainly neutrophils and macrophages. These recruited immune cells function as the scavenger to remove tissue debris and dead cells, resulting in acute inflammation. Meanwhile, immune cells themselves release factors like chemokines and cytokines to amplify inflammatory reactions. Next, the released factors, such as TGF- $\beta$ (Thannickal et al., 2003), platelet derived growth factor (PDGF) (Tang et al., 1996), interleukin-13 and interleukin-4 (Hashimoto et al., 2001), induce the limited activation and proliferation of myofibroblasts. Besides resident fibroblasts, myofibroblasts are derived from multiple cells (Hinz et al., 2007), including fibrocytes, epithelial cells via epithelialmesenchymal transition (EMT), endothelial cells via endothelialmesenchymal transition, pericytes, and smooth muscle cells related to blood vessels. In liver and pancreas, precursor cells like hepatic stellate cells (HSC) (Moreira, 2007) and pancreatic stellate cells (Apte et al., 2012) could also acquire myofibroblastic phenotype. Activated myofibroblasts migrate to injury sites, and their abilities to generate cell traction force enable them to stimulate wound closure ( $\mathrm{Li}$ and Wang, 2011). Then, the balance of ECM synthesis and degradation could be achieved by myofibroblasts, resulting in ECM homeostasis. Finally, immune cells undergo apoptosis and epithelial/endothelial cells proliferate to regenerate injury sites, leading to wound healing.

In contrast to normal wound healing process, the abnormalities of multiple factors could cause fibrosis (Biernacka et al., 2011) (Figure 2). Under some persistent stimuli, the overexpression of factors like pro-inflammatory cytokines or growth factors would overactivate (Kim et al., 2008) and interact with multiple kinases or nuclear receptors. The deficiencies of some factors would also contribute to fibrosis progression (Allen and Spiteri, 2002). Then, the abnormal signaling sustains to switch normal wound healing process to pro-fibrotic process, acting on the recruitment of excess immune cells, the induction of the myofibroblasts activation and proliferation and the promotion of ECM production. Pro-fibrotic process also promotes the activation of these factors conversely, thereby amplifying inflammatory responses and causing chronic inflammation. Finally, the sustained myofibroblasts activation would generate masses of ECM and tilt the balance in favor of synthesizing ECM to produce fibrosis. Furthermore, the pro-fibrotic process itself could contribute to secondary injury to the wound and cause a chronic vicious circle of pathological responses.

Below we divide factors modulating fibrosis progression into extracellular and intracellular groups, and discuss how they influence fibrosis progression.

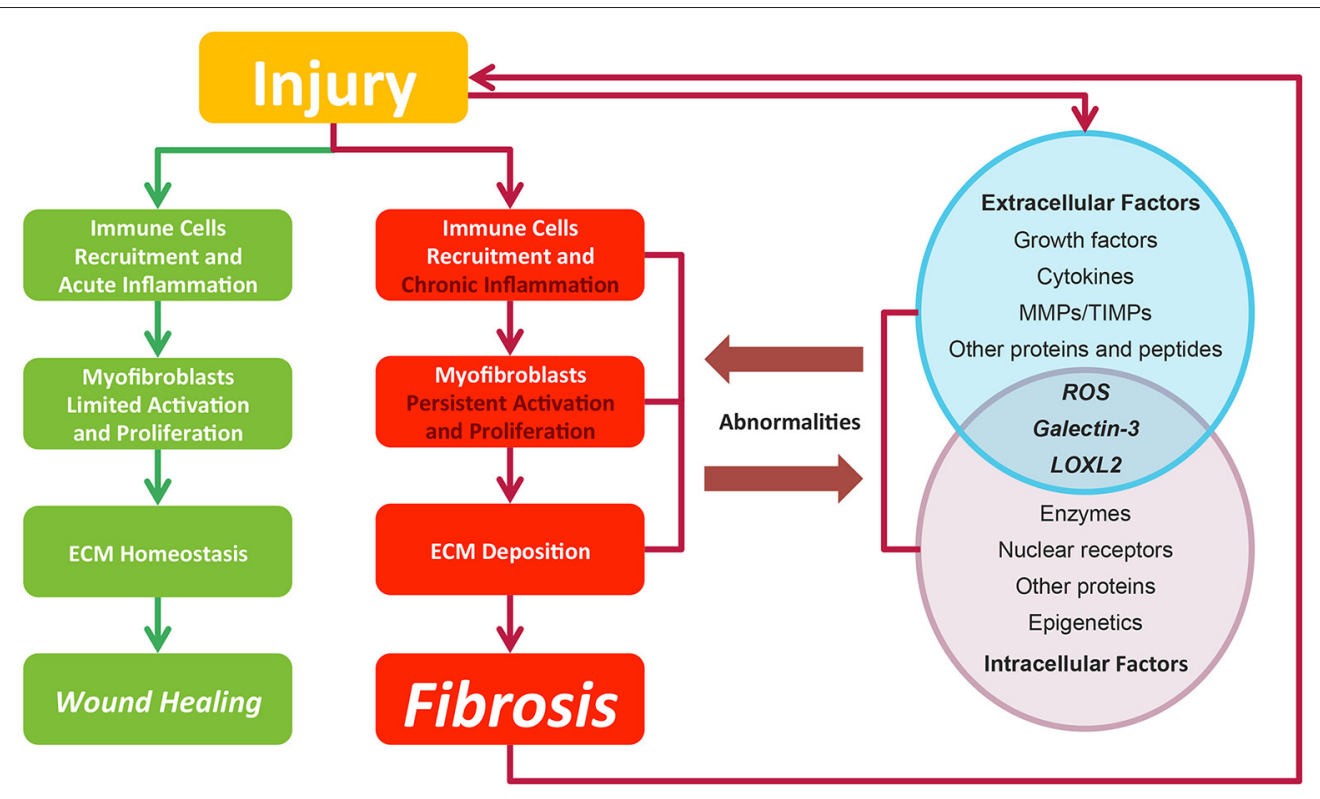

FIGURE 2 | In normal wound healing condition, there is a series of ordered process: injury, immune cell recruitment and acute inflammation, myfibroblasts limited activation, and proliferation and ECM homeostasis, leading to wound closure after injury. While in pro-fibrotic condition, pathological process including chronic inflammation, myfibroblasts persistent activation, and proliferation and ECM deposition leading to fibrosis. Fibrosis itself could result in a secondary assault. Extracellular and intracellular factors interact with each other. Their abnormalities contribute to the fibrosis progression and in return are affected by pathological changes. Green lines and blocks represent normal wound healing while red lines and blocks represent fibrosis progression. 


\section{Extracellular Factors Mediating the Progression of Fibrosis}

The majority of the fibrosis-related extracellular factors are receptor-binding ligands, such as growth factors and cytokines. These factors target adjacent and distant cells in autocrine, paracrine, or endocrine signaling pathways. Then they bind to specific receptors on cell membrane and trigger the intracellular signaling, leading to pro-fibrotic cellular responses. Other extracellular factors, mainly enzymes such as matrix metalloproteinases (MMPs) could degrade ECM to prevent its excessive accumulation.

Growth factors contain a huge family of proteins that stimulate cell growth and proliferation. They are secreted by fibroblasts, immune cells, and epithelial/endothelial cells, and are able to orchestrate cellular responses. While epithelium/endothelium are damaged, cells in these tissues massively upregulate the production of growth factors to promote the proliferation of immune cells and fibroblasts. Among growth factors, TGF- $\beta$ is the "master" modulator in fibrogensis (Meng et al., 2016), as it could provoke fibrosis through SMAD-dependent pathway (Lan, 2011) and SMADindependent pathway related to a number of other pro-fibrotic reactions (Zhang, 2009). TGF- $\beta$ signaling cascade results in differentiation of effector cells via inducing the expression of myofibroblasts hallmark $\alpha$-hallmar muscle actin( $\alpha$-SMA) (Sebe et al., 2008). In addition, TGF- $\beta$ signaling leads to the transcription of collagen I and III genes (Fine and Goldstein, 1987; Chen et al., 1999) contributing to ECM accumulation. Interacting with TGF- $\beta$, many other growth factors have distinct roles in pro-fibrotic process. For example, PDGF induces HSC proliferation and type I collagen expression via downstream focal adhesion kinase/phosphoinositide 3-kinase/ protein kinase B signaling (Reif et al., 2003). On the contrary, some growth factors have anti-fibrotic property, such as hepatocyte growth factor (HGF), the overexpression of which alleviates fibrosis in cardiomyopathic hamster through activation of MMP-1 and urokinase-type plasminogen activator (Taniyama et al., 2002). Excessive cytokines are usually secreted by immune cells, such as macrophages, neutrophils, and $\mathrm{T}$ cells in inflammation phase of wound healing. Compared with growth factors, cytokines tend to act as cell signaling transmitters to augment immunological responses and then lead to inflammation. One major type of cytokines is chemokines, which guide the recruitment of immune cells and fibroblasts to injury sites. Different immune cells are recruited by different chemokines. Neutrophils could be recruited by chemokine ( $\mathrm{C}-\mathrm{X}-\mathrm{C}$ motif) ligand 1 and chemokine (C-X-C motif) ligand 8 by binding glycosaminoglycans with receptors in slightly different ways (Sawant et al., 2016). Chemokine (C-C motif) ligand 5 has been a major factor to induce the migration of HSC in liver fibrosis (Seki et al., 2009). Another type of cytokines is T cell cytokines, which are mainly secreted by activated $\mathrm{T}$ lymphocytes. They include interleukins, interferons and tumor necrosis factors (TNF), mediating adaptive immune responses and inflammation that might promote fibrosis. For example, IL- 6 has been reported to shift the tissue repair to a chronic inflammatory state by signal transducer and activator of transcription 3(STAT3) signaling pathway in peritoneal fibrosis (Fielding et al., 2014). In contrast, some cytokines have anti-fibrotic effects. It has been reported that interferon- $\gamma$ down-regulated the Adenosine A2A receptor signaling to prevent the production of type I collagen in HSC (Block and Cronstein, 2010). Moreover, some T cell cytokines, such as TNF- $\alpha$, exhibit two-sided effects, pro-fibrotic or antifibrotic effect depending on the alternative status of macrophages and micro-environment (Redente et al., 2014).

MMPs are the extracellular endopeptidases degrading ECM including collagens, proteoglycans, laminins, and fibronectin. Tissue inhibitor of metalloproteinases (TIMPs) work as the inhibitors of MMPs. The balance of MMPs and TIMPs modulates the process throughout fibrosis development, including the formation of multiple cell injuries, the activation of latent cytokines and myofibroblasts and mainly, the maintenance of the homeostasis of ECM (Giannandrea and Parks, 2014). Some MMPs have pro-fibrotic functions whereas some have antifibrotic according to cell types and phases. The dysregulation of MMP-19 has been proved to cause the degradation of normal liver ECM and initiate liver injury (Jirouskova et al., 2012). Conversely, MMP-2 has been reported to cleave type I collagen and attenuate collagen deposition by HSC, inhibiting liver fibrosis (Radbill et al., 2011). As to TIMPs, they could inhibit or activate fibrosis via MMPs. For example, TIMP-3 inhibits MMPs to induce inflammation (Gill et al., 2010) in lung injury, and TIMP-1 has been found to play a dual role in liver fibrosis (Wang H. et al., 2011).

Other extracellular factors include a wide range of proteins and peptides. They mainly guide the differentiation of myofibroblasts, and are closely related to each other and growth factors. For example, the hedgehog $(\mathrm{Hh})$ signaling pathway mediates EMT during the fetal development, and responds to injury through the repression of epithelial marker epithelial-cadherin by Snail and Twist. Overactivation of $\mathrm{Hh}$ signaling pathway contributes to biliary fibrosis and related liver fibrosis (Omenetti et al., 2008). In fibrotic kidney, the upregulated Wnt signaling has been reported to result in abundant of $\beta$-catenin. The signaling regulates genes such as Twist, LEF1 to induce EMT, thus to aggravate disease (He et al., 2009).

\section{Intracellular Factors Mediating the Progression of Fibrosis}

Intracellular factors, mainly multiple kinases, propagate the signaling received by cells through phosphorylation and other pathways. A common consequence of the signaling is that, transcription activators or inhibitors translocate into nucleus to regulate fibrosis-related gene expression and cell responses. In certain inflammatory pathways, intracellular factors also modulate the expression of extracellular factors, such as growth factors and cytokines, and secrete them out of cells to amplify inflammatory responses. Besides, epigenetic factors are emerging as a new way to affect fibrosis-related gene expression.

Intracellular factors include a number of kinases. In inflammation phase, many upstream factors, such as TGF- $\beta$, TNF- $\alpha$, and epidermal growth factors initiate mitogen-activated 
protein kinase (MAPK) pathway. An element of MAPK pathway, mitogen-activated protein kinase-activated protein kinase-2 mediates myofibroblasts differentiation and regulates the gene expression of several matrix proteins such as colla2, col3a1, and lox (Vittal et al., 2013). Another important intracellular signaling, mechanistic target of rapamycin (mTOR) pathway is activated by Wnt and TNF- $\alpha$. Then, mTOR pathway activates ribosomal protein S6 kinase $\beta-1$ and modulates protein p21 or p27, which regulates the cell cycle of many cells including fibroblasts. In addition, the inhibition of mTOR pathway reduces collagen deposition and cardiac fibrosis (Chen et al., 2012). Besides serving as amplifiers of signal transduction, some intracellular enzymes such as cathepsin $\mathrm{K}$, which belongs to lysosomal cysteine proteases, have been proved to be able to degrade ECM in lysosome after phagocytosis (Fukumori et al., 2003; Buhling et al., 2004).

Nuclear receptors are receptors located in cytoplasm and nucleus that could receive signals from intracellular ligands and bind to DNA to regulate gene expression. For example, peroxisome proliferator activated receptor $\gamma(\operatorname{PPAR}-\gamma)$, may directly regulate type I collagen gene (Yang et al., 2006) and block TGF- $\beta$ signaling (Ghosh et al., 2009). Another nuclear receptor, farnesoid-X receptor (FXR), exhibits anti-fibrotic effect via the reduction of proliferating cholangiocytes and subsequent reduction of TGF- $\beta$ (Liu et al., 2003). The activation of FXR also decreases a series of pro-fibrotic factors including TIMP-1, collagens, $\alpha$-SMA, and MMP-2 (Zhang et al., 2009).

Nowadays, epigenetics including microRNAs, DNA methylation and lncRNAs, are found involved in machinery of pro-fibrotic process mainly through regulating fibrosis-related gene expression. Some microRNAs are found to negatively regulate translation of ECM components. Among them, miR-21 induces extracellular-signal regulated kinase/MAPK activity via the inhibition of Spry1 to protect cardiac fibroblasts survival (Thum et al., 2008). It has been reported that the levels of DNA methylation at specific $\mathrm{CpG}$ sites of pro-fibrotic genes (PPAR $\alpha, P P A R \delta, T G F \beta 1$, Collagen1A1, and PDGF $\alpha)$ differ among different fibrosis stages in NAFLD (Zeybel et al., 2015).

There are factors that affect fibrosis process both extraand intracellularly, including reactive oxygen species (ROS), galectin-3 and lysyl oxidase homolog 2 (LOXL2). ROS can be generated through tissue injuries, cell damages and NADPH oxidase activities. Extracellular ROS targets latency-associated peptides and then activates TGF- $\beta$ signaling while intracellular oxidative stress induces p53-dependent apoptosis in lung fibrosis via the caspases-9/3 activation in mitochondria (Cheresh et al., 2013). As to galectin-3, extracellular galectin-3 induces $T$ cell apoptosis and plays a dual function inside and outside cells (Li et al., 2014). Another factor LOXL2 is generally considered as extracellular enzyme that promotes collagen production and crosslink with collagen fibers in response to mechanical stress (Yang et al., 2016). While on the other hand, intracellular LOXL2 has been reported to induce EMT in carcinoma progression (Peinado et al., 2005).

Many studies proved that different fibroproliferative diseases share common underlying mechanisms (Wenzke et al., 2012). The existence of common mechanisms facilitates the complete interpretation of fibrosis pathogenesis and enhances our understanding of fibrosis-related diseases. On this basis, it is necessary to reconsider targets involved in these mechanisms and evaluate their potential roles in fibrosis treatment across tissues and organs.

\section{DRUGS AND TARGETS IN FIBROSIS}

Motivated by huge clinical burdens, continuous intense researches on drug targeting fibrosis have been conducted, many of which have led to clinical trials. Due to the strong associations between inflammation and fibrosis, more efforts have been devoted to anti-inflammation drugs in the past few years (Dinwiddie, 2005). Nowadays, new targets and drugs for fibrosis are constantly emerging with the progress in understanding fibrosis pathology. Here we summarize them in Tables 1-4, including single (Tables 1-3) and multi component (Table 4) drugs with their verified and potential targets in fibrosis.

\section{Single-Component Drugs Targeting Extracellular Factors Mediating Fibrosis}

Nowadays, most approved and investigational drugs are singlecomponent drugs, which only contain one organic component and have distinct targets. As we described previously, fibrosis progression results from a combination of the abnormalities of extracellular and intracellular factors. Drugs targeting extracellular factors are prevalent, about $60 \%$ of known targets are receptors located on cell membrane mainly because the extracellular targets are accessible and serve as upstream signals (Overington et al., 2006), and so are the targets of fibrosisrelated drugs. The binding of receptors and ligands triggers the downstream signaling, thus the blockade of receptors or ligands is considered to be an effective choice to alleviate fibrosis (Table 1).

The majority of anti-fibrosis drugs targeting extracellular factors are inhibitors of ligands such as growth factors, cytokines and MMPs. Most inhibitors could directly bind to the active sites of targets. The majority of approved inhibitor drugs in Table 1 target TNF, which are widely used in fibrosis-related diseases and could suppress the action of TNF through multiple mechanisms. These drugs include small molecules Thalidomide and Pomalidomide (Weingartner et al., 2012), recombinant protein Etanercept and monoclonal antibodies Belimumab. Thalidomide and Etanercept have completed the phase II trial in IPF (Raghu et al., 2008; Horton et al., 2012) while Belimumab has completed the phase II trial in SSc. Besides, some inhibitor drugs targeting growth factors are still under investigation. For example, Disitertide, a synthetic peptide derived from TGF$\beta$ type III receptor, inhibits the binding of TGF- $\beta$ and its receptor and exhibit anti-fibrotic function (Ezquerro et al., 2003). Drugs that inhibit interleukins are always monoclonal antibodies. Tralokinumab, a human IgG4 monoclonal antibody, shows proapoptotic effects via IL-induced apoptotic factors in IPF (Murray et al., 2014). Many natural products act as inhibitor drugs like Dioscin, which is a monomer extracted from Dioscoreae Rhizoma and could ameliorate liver fibrosis (Liu et al., 2015; Zhang et al., 2015a,b; Gu et al., 2016; Xu et al., 2017; Yin et al., 


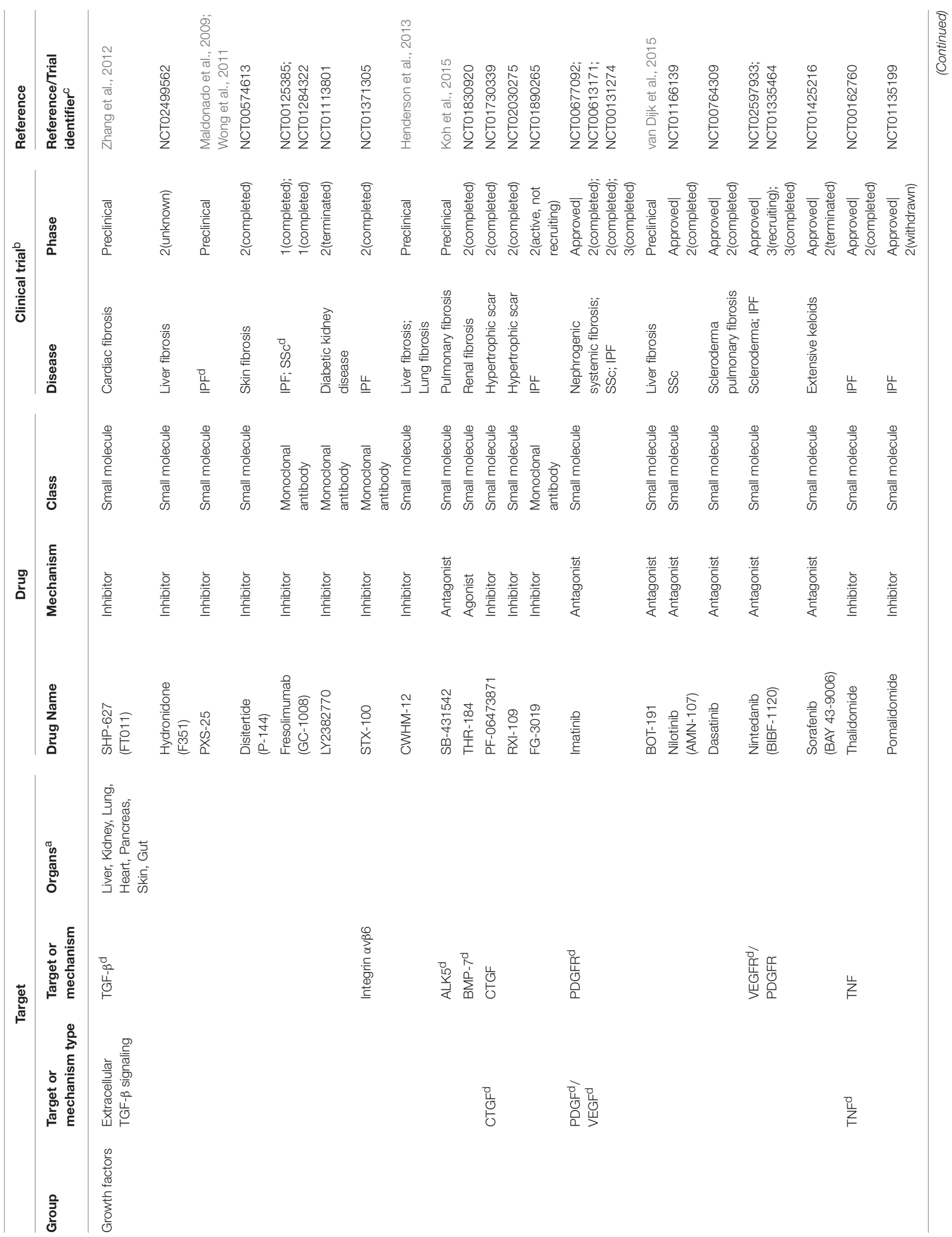




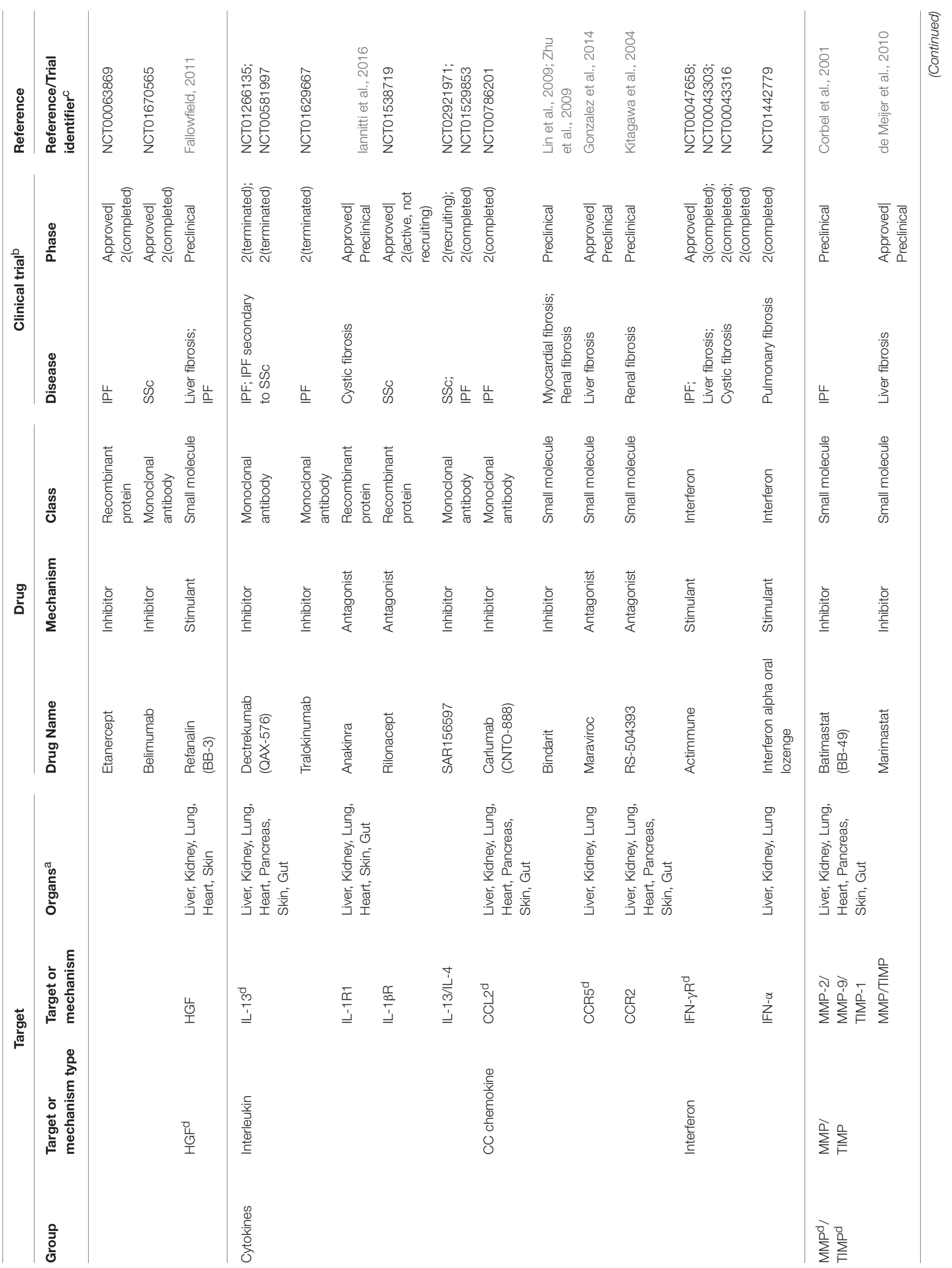




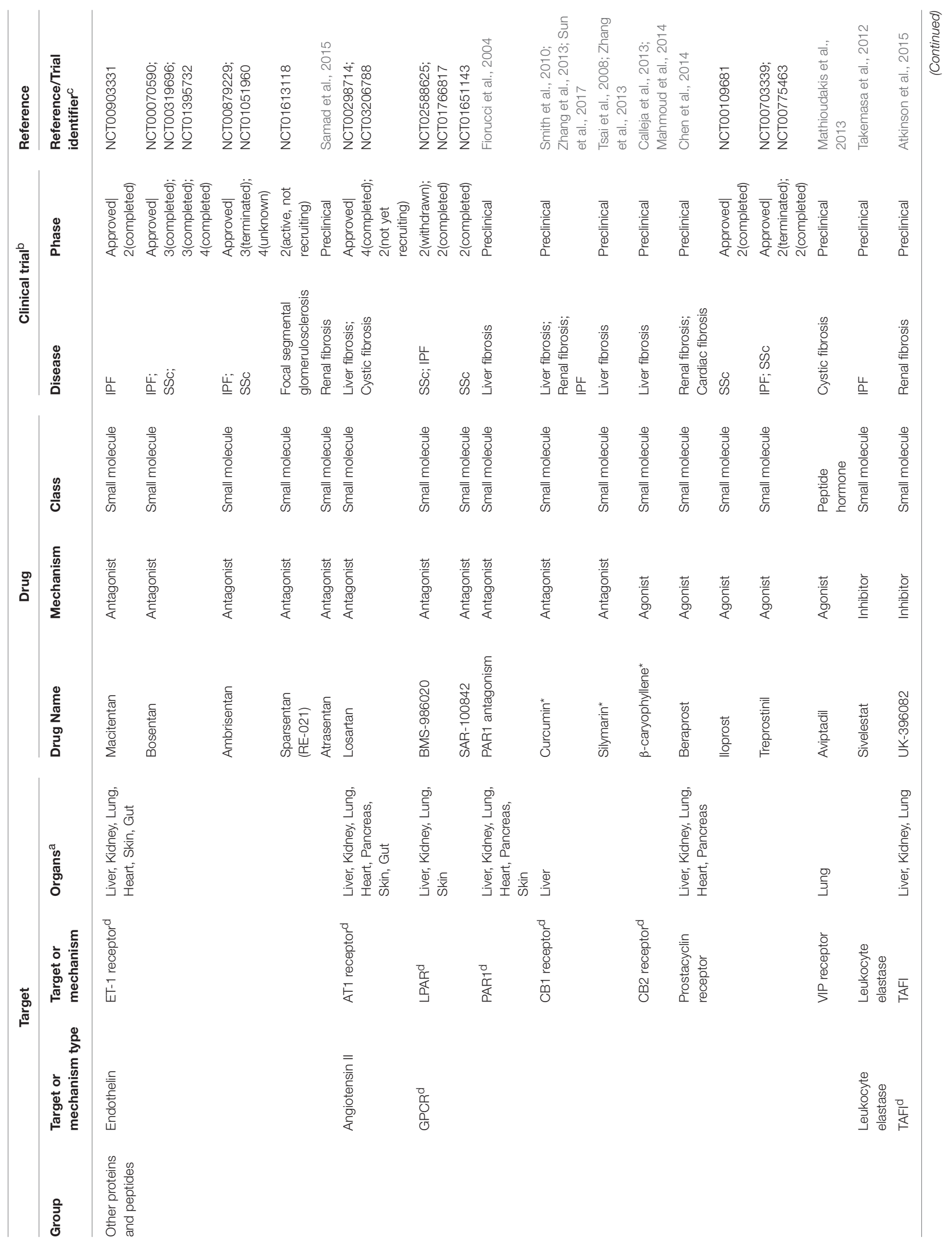




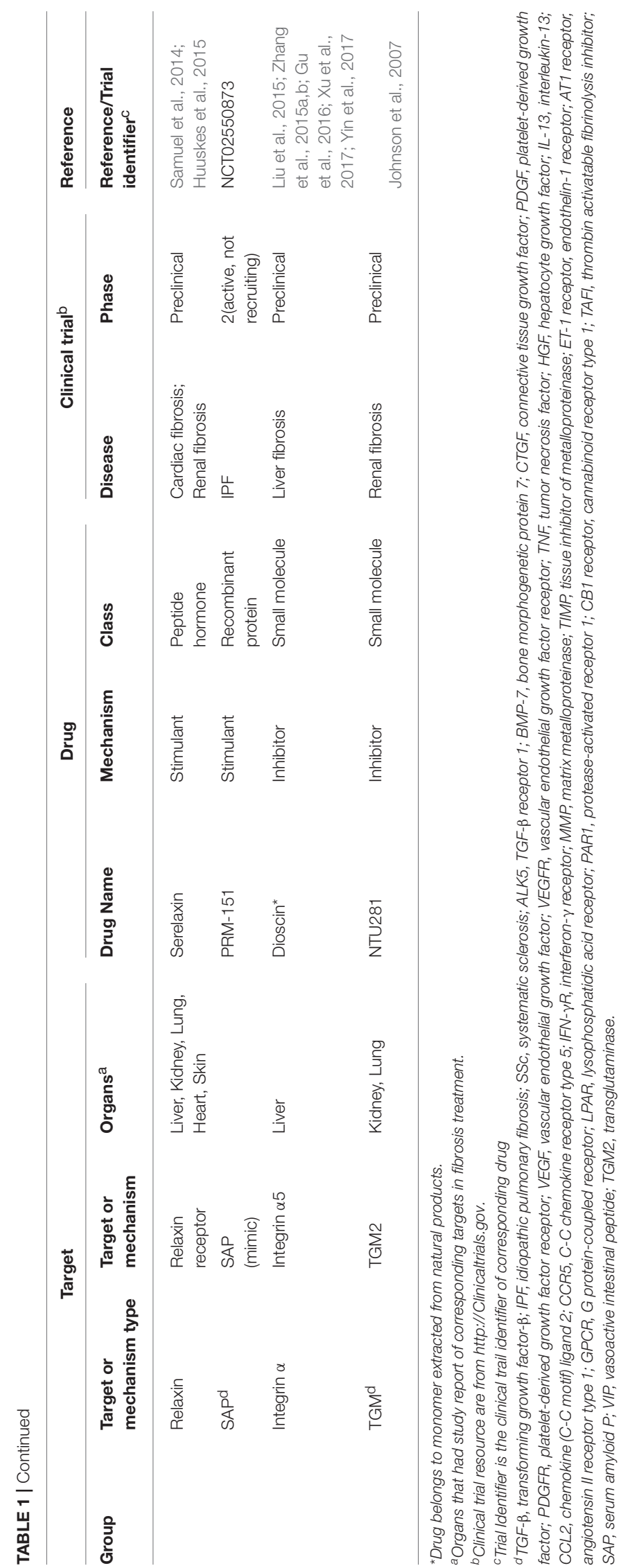

2017). In addition, some preclinical drugs inhibit MMPs, like Marimastat, which simultaneously down-regulates MMPs gene expression and MMPs activities. However, Marimastat reduces inflammation and liver injuries while increases fibrosis in mice model. This may result from the indiscriminative inhibition of MMPs, some of which function to degrade ECM (de Meijer et al., 2010).

Compared with inhibitor drugs, antagonists achieve the same inhibition effect by targeting cell membrane receptors to dampen downstream signaling. These small molecules bind to receptors without effectively activating them. The receptors of PDGF, vascular endothelial growth factor, endothelin (ET), and angiotensin all have approved antagonist drugs. An antagonist for tyrosine kinase receptors of PDGF, Imatinib, has showed protective effect by reducing differentiation of resting fibroblasts in SSc mice model (Akhmetshina et al., 2009). However, it did not show efficacy in phase II clinical trial in IPF (Daniels et al., 2010) and the high-dose of Imatinib may lead to severe adverse events (Khanna et al., 2011). Macitentan, a dual antagonist of $\mathrm{ET}_{\mathrm{A}}$ and $\mathrm{ET}_{\mathrm{B}}$ receptor, is beneficial for lung fibrosis. Similarly, another drug Losartan targeting angiotensin II receptor has been evaluated in IPF patients (Couluris et al., 2012). Some preclinical antagonist drugs including Maraviroc (Gonzalez et al., 2014), Atrasentan (Ritter et al., 2014), and PAR1 antagonists (Fiorucci et al., 2004) were under investigation for fibrosis treatment.

On the contrary, many drugs exert their therapeutic effects by activating their targets. Many anti-fibrotic receptors can be targets of these exogenous agonists that augment the downstream biological responses to suppress fibrosis. An approved agonist drug in this category is Iloprost, which can reverse right ventricle fibrosis by re-establishing collagen balance (Gomez-Arroyo et al., 2015). Another agonist of vasoactive intestinal peptide, Treprostinil, reduces inflammation and collagen deposition (Manitsopoulos et al., 2015). Other anti-fibrotic agonists for cell membrane receptors include Aviptadil, INT-767 (Baghdasaryan et al., 2011) and Beraprost (Kaneshige et al., 2007).

Moreover, a few drugs are synthetic proteins that bind receptors to serve as stimulants and perform the same functions as native proteins. An approved drug, synthetic interferon- $\gamma$, Actimmune, has completed phase II or phase III study in multiple fibrosis including IPF (Skaria et al., 2015), liver fibrosis (Muir et al., 2006), and cystic fibrosis (Moss et al., 2005). Another stimulant Refanalin, a HGF mimetic, is a potential drug for liver fibrosis (Fallowfield, 2011; Pellicoro et al., 2014).

\section{Single-Component Drugs Targeting Intracellular Factors Mediating Fibrosis}

Compared with extracellular factors, intracellular targets are less popular owing to their inaccessibility. Drugs targeting intracellular factors are less varied because most of them are small molecules. Small molecules could readily translocate into cytoplasm while large molecules such as monoclonal antibodies face more challenges to cross the plasma membrane (Imai and Takaoka, 2006). Nevertheless, more and more studies concerned intracellular factors as targets in recent years, and numerous candidate targets are identified in cytoplasm, nucleus, 


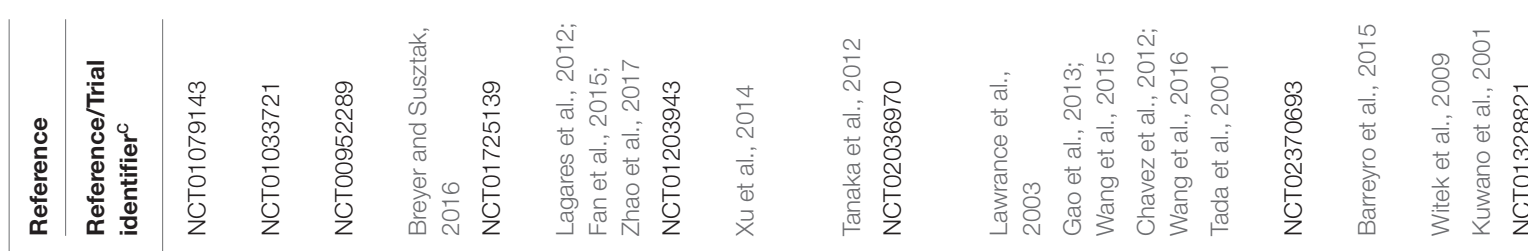

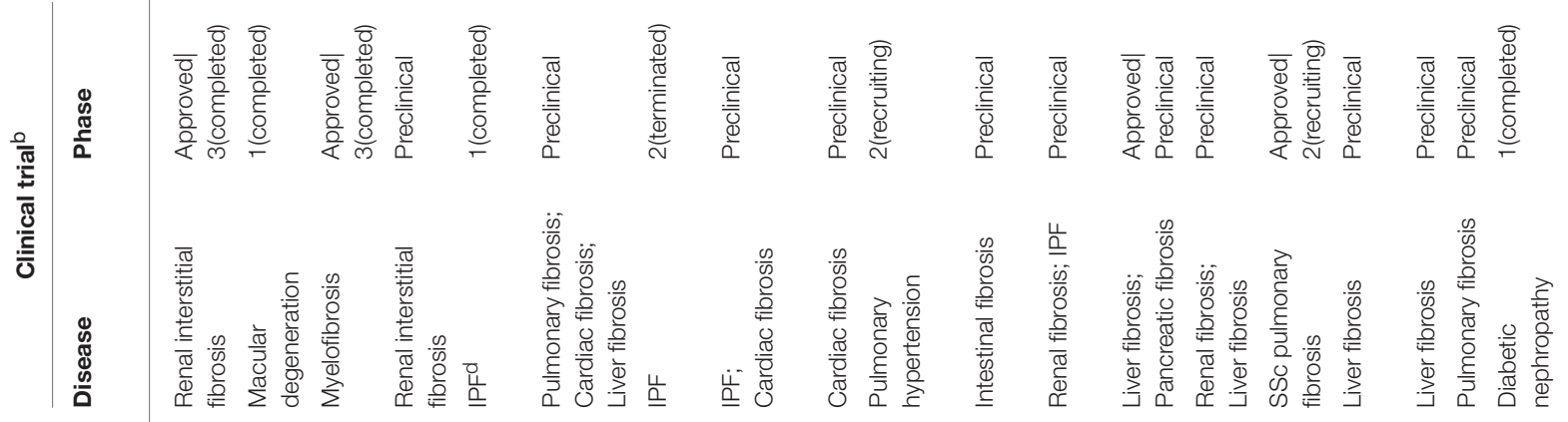
$111\|1\| \Pi\|\Pi\| M$

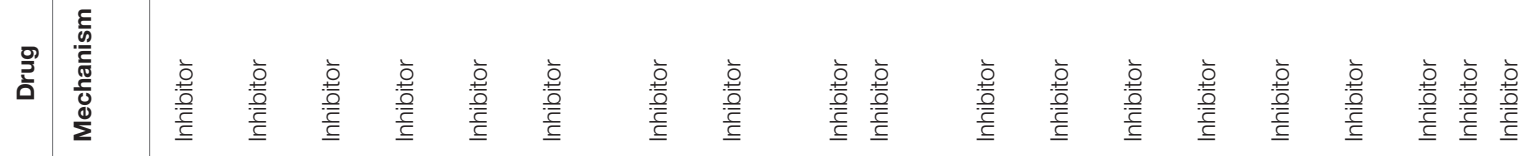

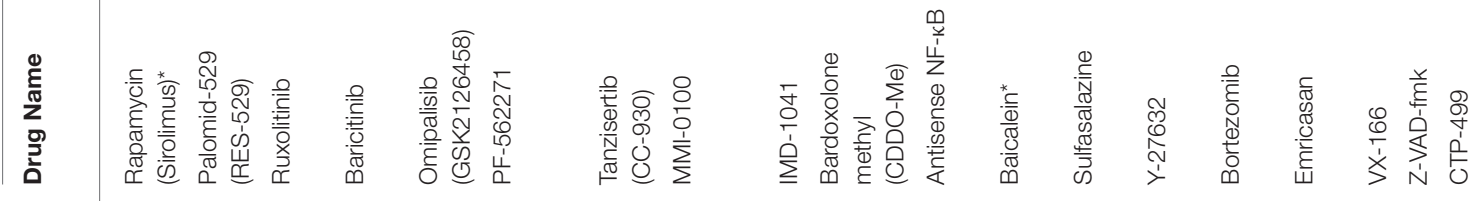
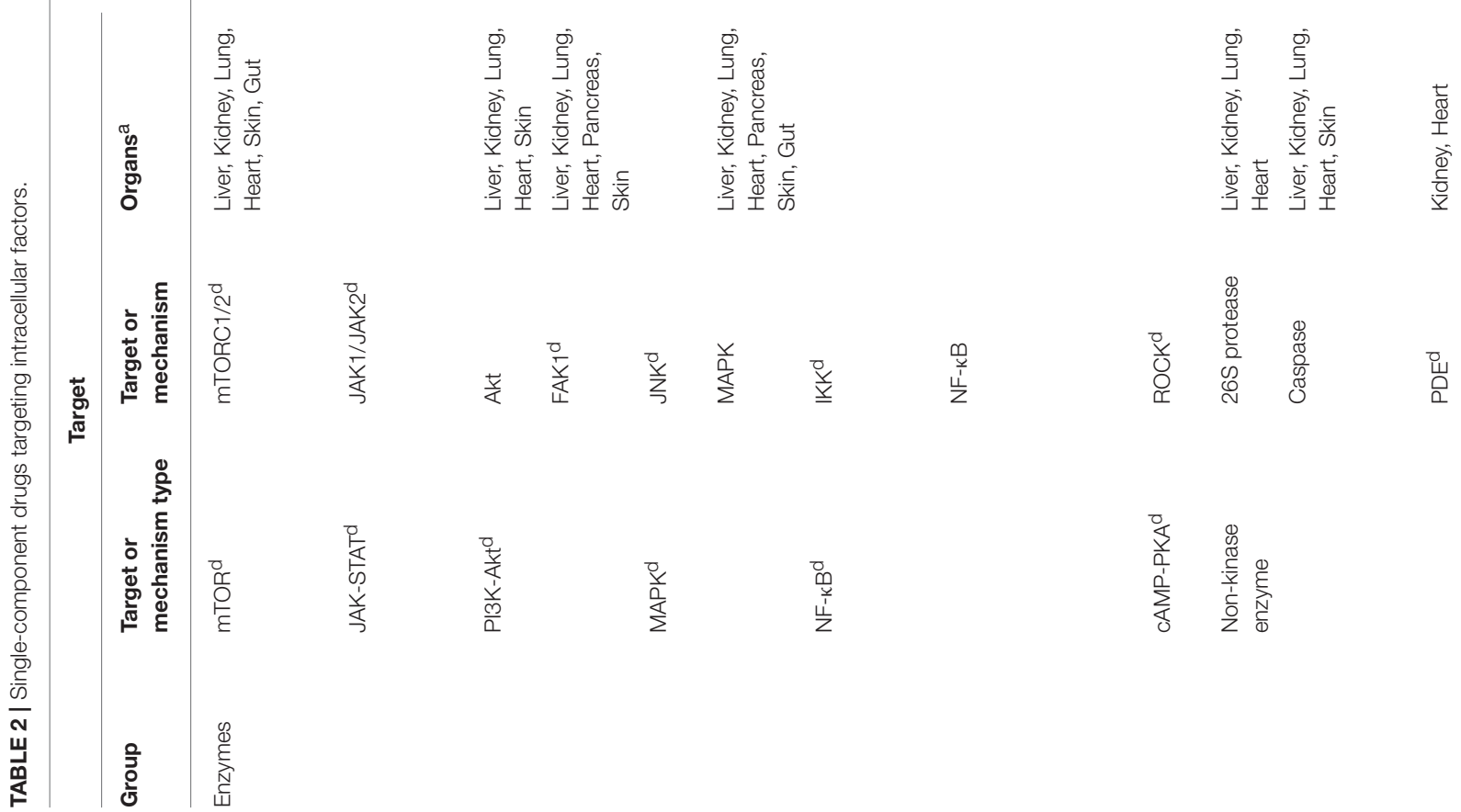

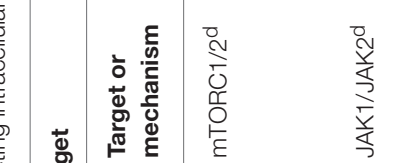

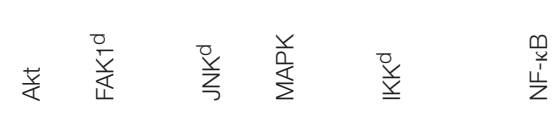

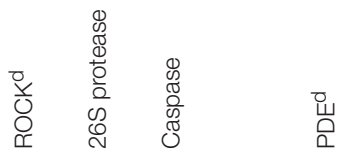

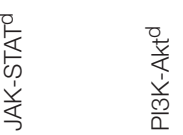

$\frac{\sqrt{2}}{\frac{0}{2}}$

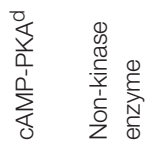




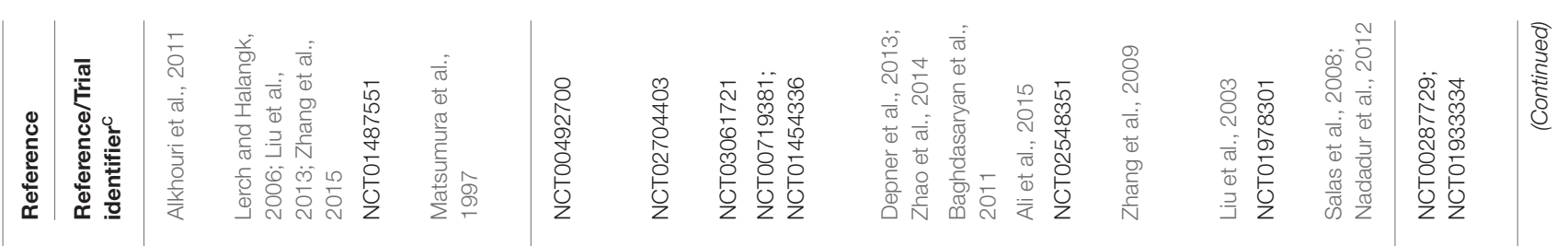

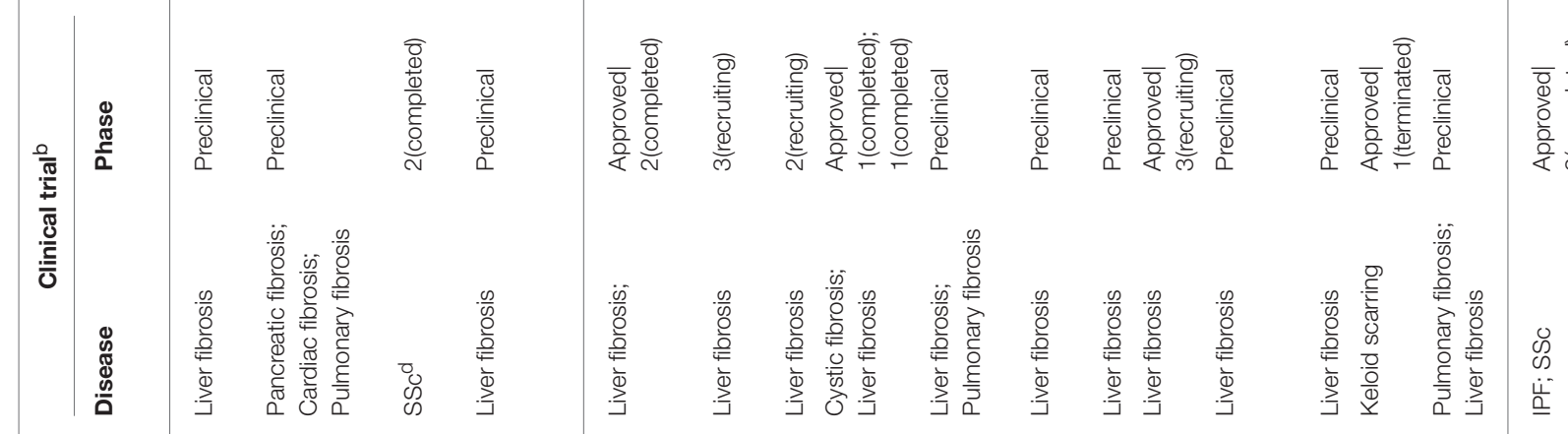

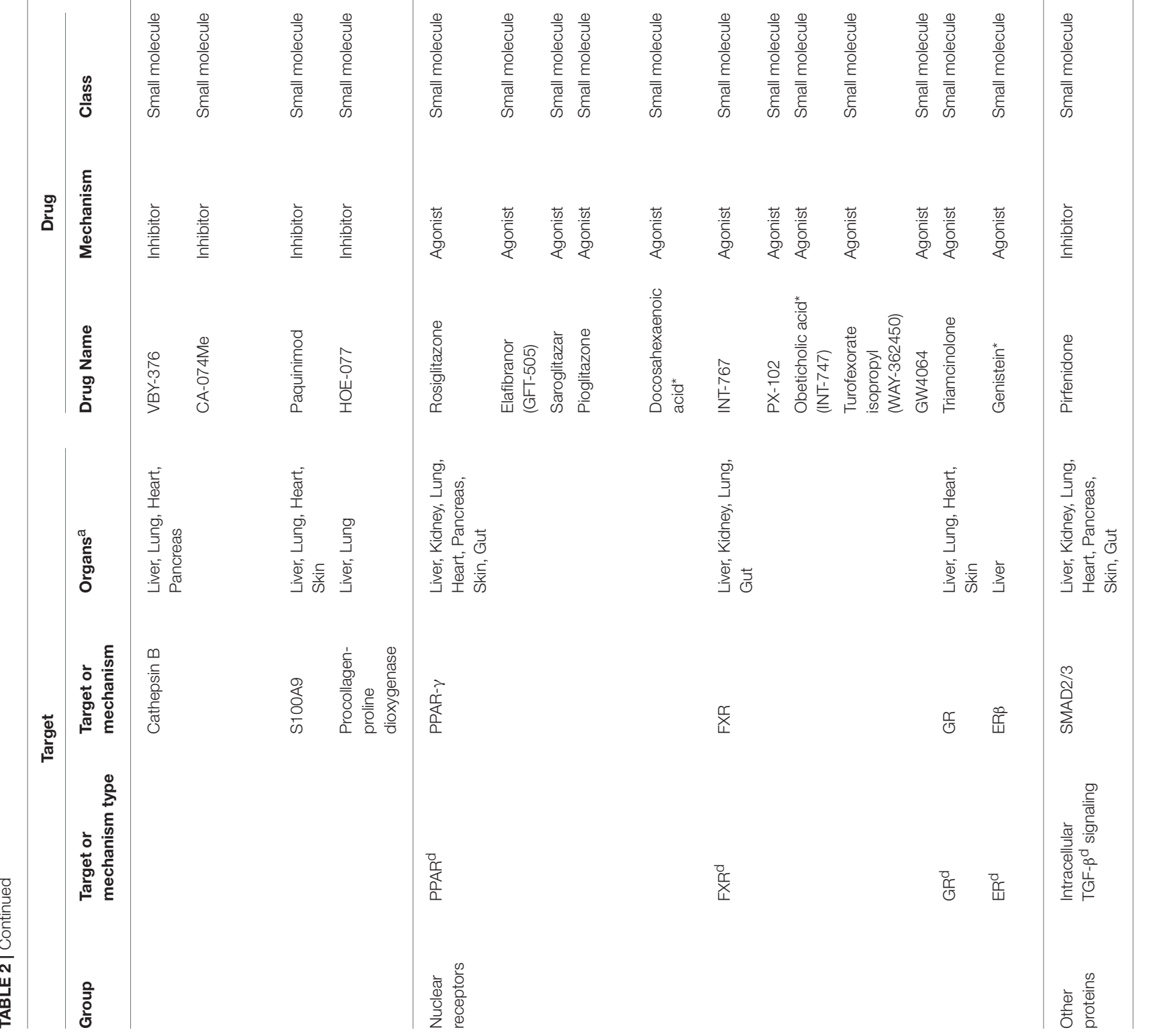




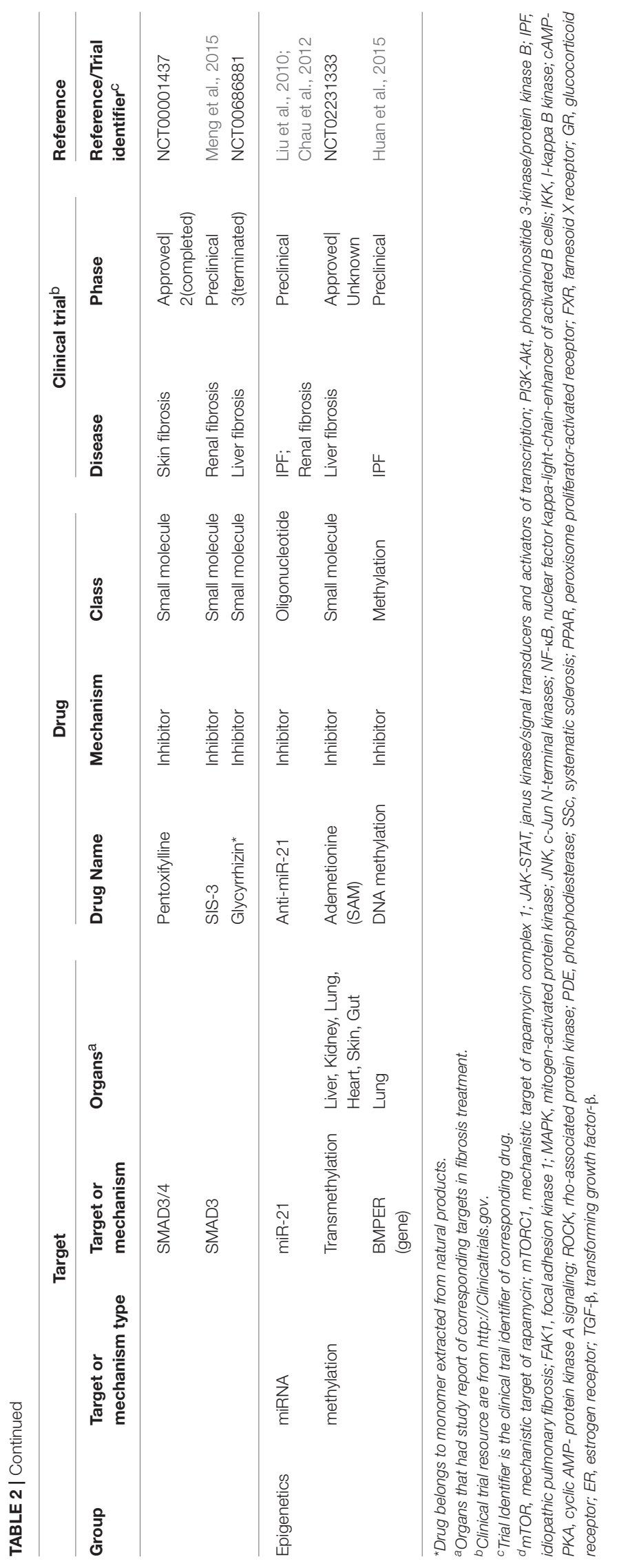

and mitochondrion. Many approaches, including increasing membrane permeation, combination with supercharged proteins and activating transport through receptors, were implemented to deliver drugs across cell membrane (Mitragotri et al., 2014).

Fibrosis drugs targeting intracellular factors are summarized and classified into four categories: enzymes, nuclear receptors, other proteins, and epigenetics (Table 2). Many drugs acting through intracellular factors are also inhibitors. These drugs inhibit a wide range of kinases located in cytoplasm, and consequently suppress the translocation of transcription factors that drive the expression of pro-fibrotic genes. Rapamycin and Sirolimus are approved drugs that inhibit mTOR. Rapamycin prevents the activation of macrophages and myofibroblasts and the subsequent release of TGF- $\beta$ in chronic kidney disease (CKD) (Chen et al., 2012). Sirolimus shows anti-inflammatory and antifibrotic effects in IPF (Tulek et al., 2011). Besides kinases, there are many other intracellular proteins that serve as potential targets for fibrosis management. Pirfenidone, one of the IPF drugs, has completed phase III trial in IPF patients with alleviated disease progression and acceptable side effects (King et al., 2014). The potential mechanism of Pirfenidone is inhibiting the nuclear accumulation of intracellular proteins SMAD2/3 to regulate TGF- $\beta$ signaling (Choi et al., 2012). Other approved inhibitor drugs include Ruxolitinib for bone marrow fibrosis (Wilkins et al., 2013), Paquinimod for SSc (Stenstrom et al., 2016), and Pentoxifylline (Okunieff et al., 2004) combined with vitamin E (Jacobson et al., 2013).

In addition, there are also some nuclear receptors located in cytoplasm and nucleus, which could be activated by small molecule agonists, such as PPAR. Rosiglitazone, a PPAR- $\gamma$ agonist, has anti-fibrotic effect as a consequence of activating MMP-1 and elevating HGF expression in patients with systemic sclerosis-related interstitial lung disease (Bogatkevich et al., 2012). Other approved PPAR targeting drugs like Elafibranor and Pioglitazone, have entered phase II and phase I studies, respectively. Obeticholic acid is an approved drug entering phase III study that decreases inflammation and fibrosis in NASH patients via activating FXR signaling (Verbeke et al., 2016).

Epigenetics are very different types of fibrosis therapies. The most studied epigenetics-based therapy for fibrosis is microRNA. MicroRNA could be neutralized by specific antimiRNA oligonucleotides delivered into cells. Among them, anti-miR-21 has been reported to inhibit miR-21 activity and ameliorate fibrosis progression through PPAR signaling in CKD (Chau et al., 2012). Another strategy is the intervention of DNA methylation for proteins such as BMP endothelial cell precursorderived regulator (BMPER), which acts as the regulator of fibroblasts activation. Altering methylation on BMPER gene has been reported to decrease BMPER level and thus to inhibit fibroblasts activity (Huan et al., 2015). Besides, some drugs targeting both extracellular and intracellular factors are also incorporated (Table 3). A majority of them are antioxidants, including an approved drug $\mathrm{N}$-acetylcysteine (Zhang et al., 2014).

\section{Multi-Component Drugs Used for Fibrosis}

Differed from single-component drugs that target a single protein or other simple targets, multi-component drugs contain 


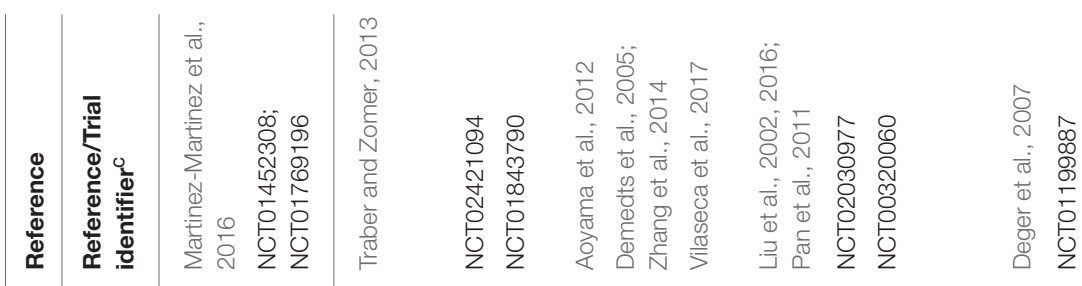

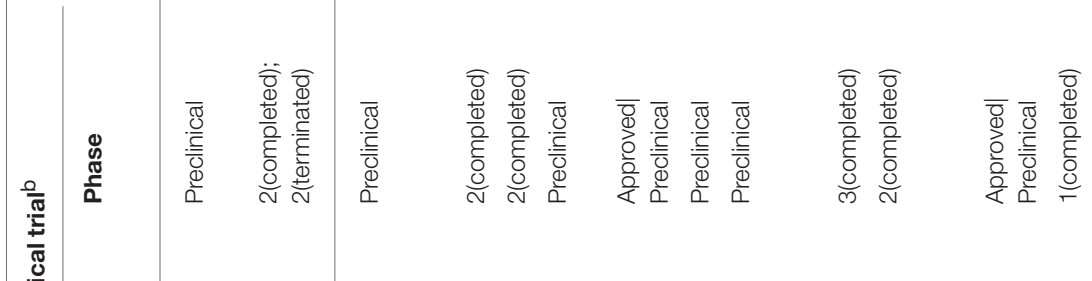

U.

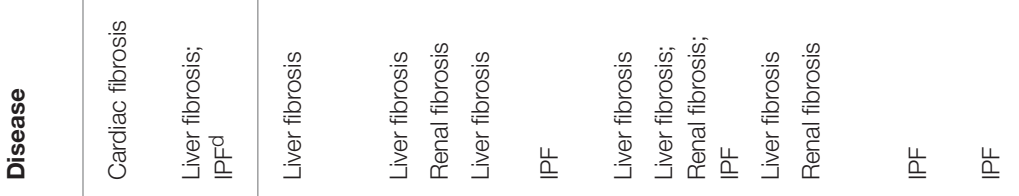

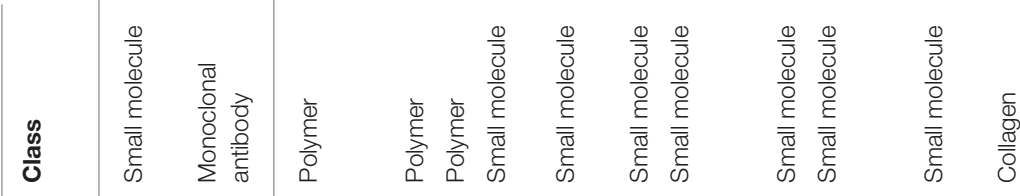

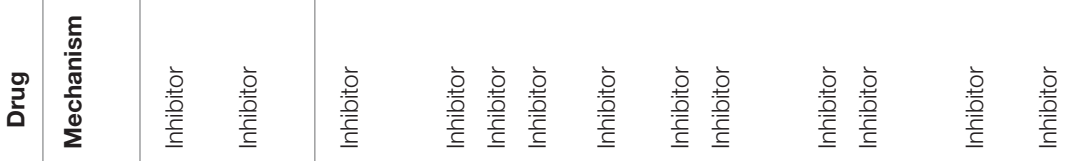

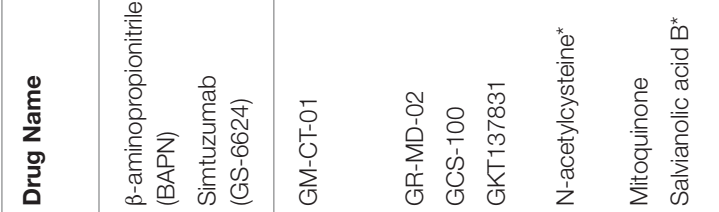

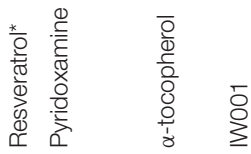

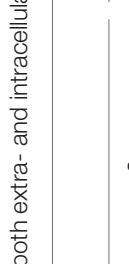

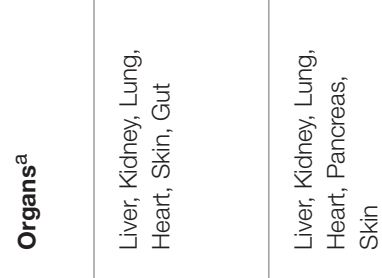

.

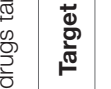

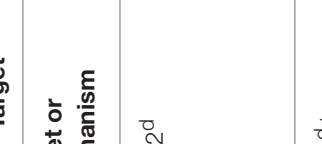

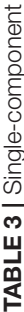

官

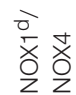

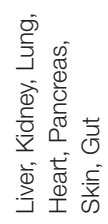

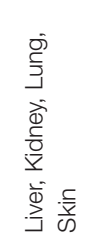

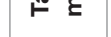

임

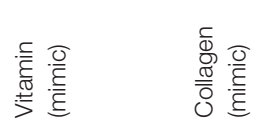

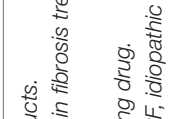

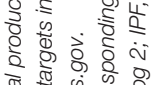

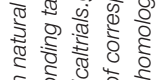

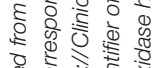

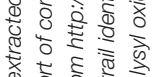

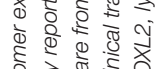

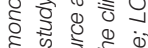

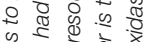

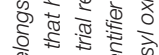

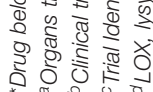


TABLE 4 | Multi-component drugs.

\begin{tabular}{|c|c|c|c|c|}
\hline \multicolumn{2}{|c|}{ Drug } & \multicolumn{2}{|c|}{ Clinical trial $^{\mathrm{a}}$} & \multirow{2}{*}{$\begin{array}{l}\text { Reference } \\
\text { Reference/Trial identifier }^{b}\end{array}$} \\
\hline Drug Name & Mechanism & Disease & Phase & \\
\hline Fuzhenghuayu capsule (FZHY) & $\mathrm{TGF}-\beta^{\mathrm{C}} / \mathrm{MMP}-2^{\mathrm{C}}$ & Liver fibrosis & $\begin{array}{l}\text { 2(completed); } \\
\text { 4(recruiting) }\end{array}$ & $\begin{array}{l}\text { NCT00854087; } \\
\text { NCT02241616 }\end{array}$ \\
\hline Qishenyiqi (QSYQ) & $\mathrm{TNF}^{\mathrm{C}} / \mathrm{TGF}-\beta / \beta$-Catenin & Ischemic heart failure & 2(recruiting) & NCT02875639 \\
\hline Qushi Huayu Decoction (QHD) & $\operatorname{ROS}^{\mathrm{C}}$ & Liver fibrosis & Preclinical & Feng et al., 2017 \\
\hline Herbal compound 861 (Cpd 861) & TGF- $\beta / \mathrm{MMP}-1 / \mathrm{TIMP}-1^{\mathrm{C}}$ & Liver fibrosis & Preclinical & Hou et al., 2016 \\
\hline Xiao-Chai-Hu Tang (XCHT) & IL-6 ${ }^{\mathrm{C}} / \mathrm{TNF}-\alpha /$ Bax protein & Liver cancer & 2(completed) & $\begin{array}{l}\text { NCT00040898; } \\
\text { Zhou et al., } 2012\end{array}$ \\
\hline Dahuangzhechong pill (DHZCP) & $\alpha-\mathrm{SMA}^{\mathrm{C}} / \mathrm{TNF}-\alpha / \mathrm{IL}^{-13 / p 38} \mathrm{MAPK}^{\mathrm{C}} / \mathrm{ERK}^{\mathrm{C}}$ & Liver fibrosis & Preclinical & Cai et al., 2010 \\
\hline Han-dan-gan-le & ROS/collagen & Liver fibrosis & Preclinical & Li et al., 1998 \\
\hline Qianggan-Rongxian Decoction & - & Liver fibrosis & Preclinical & Li et al., 2008 \\
\hline Yi-gan-kang granule & type I collagen/TIMP-1 & Liver fibrosis & Preclinical & Yao et al., 2005 \\
\hline Ginkgo biloba extract & TGF- $\beta$ & Liver fibrosis & Preclinical & Ding et al., 2005 \\
\hline Rosa laevigata Michx (RLTS) & $\begin{array}{l}\text { ROS/CYP2El }{ }^{\mathrm{C}} / \mathrm{TGF}-\beta / \mathrm{SMAD} / \mathrm{FAK}^{\mathrm{C}}-\mathrm{PI} 3 \mathrm{~K}^{\mathrm{C}}- \\
\mathrm{Akt}^{\mathrm{C}}-\mathrm{p} 70 \mathrm{~S} 6 \mathrm{~K}^{\mathrm{C}} / \mathrm{MAPK}\end{array}$ & Liver fibrosis & Preclinical & Dong et al., 2015 \\
\hline Liuweiwuling (LWWL) tablets & TGF- $\beta / \mathrm{SMAD} / \mathrm{NF}-\kappa \mathrm{B}^{\mathrm{C}}$ & Liver fibrosis & Preclinical & Liu et al., 2017 \\
\hline Xuefuzhuyu (XFZY) decoction & $\mathrm{HIF-YC} / \mathrm{DDAH} \mathrm{H}^{\mathrm{C}} / \mathrm{ADMA}^{\mathrm{C}} / \mathrm{NEGF}^{\mathrm{C}}$ & Liver fibrosis & Preclinical & Zhou et al., 2014 \\
\hline Diwu Yanggan (DWYG) & TGF- $\beta / \mathrm{BMP}-7^{\mathrm{C}}$ & Liver fibrosis & Preclinical & Shen et al., 2014 \\
\hline Ocimum gratissimum extracts (OGEs) & $\mathrm{ROS} / \alpha-\mathrm{SMA}$ & Liver fibrosis & Preclinical & Chiu et al., 2014 \\
\hline Yin-Chiao-San (YCS) & $\mathrm{ROS} / \mathrm{TNF}-\alpha$ & $\mathrm{IPF}^{\mathrm{C}}$ & Preclinical & Yen et al., 2007 \\
\hline Renshen pingfei decoction & TGF- $\beta / S M A D 3$ & IPF & Preclinical & Chen et al., 2016 \\
\hline Hu-qi-yin & TGF- $\beta$ & IPF & Preclinical & Zhou et al., 2007 \\
\hline $\begin{array}{l}\text { Decoction for Strengthening Qi and } \\
\text { Replenishing Lung (DSQRL) }\end{array}$ & - & IPF & Preclinical & Zhang et al., 2008 \\
\hline Modified Kushen Gancao Formula (mKG) & TGF- $\beta / \mathrm{IL}-6 / \mathrm{IL}-17 \mathrm{~A}$ & IPF & Preclinical & Gao et al., 2016 \\
\hline Sho-seiryu-to (TJ-19) & ROS & IPF & Preclinical & Yang et al., 2010 \\
\hline Hochu-ekki-to (TJ-41) & IL-5/IL-4/IFN- $\gamma$ & IPF & Preclinical & Tajima et al., 2007 \\
\hline Shenlong Decoction & MMsP/TIMPs & IPF & Preclinical & Lu et al., 2010 \\
\hline Yupingfeng & HMGB1 ${ }^{\mathrm{C}} / \mathrm{TGF}-\beta$ & IPF & Preclinical & Cui et al., 2015 \\
\hline Danggui-Buxue-Tang (DBTG) & TNF- $\alpha / T G F-\beta$ & IPF & Preclinical & Lv et al., 2012 \\
\hline
\end{tabular}

${ }^{a}$ Clinical trial resource are from http://Clinicaltrials.gov.

${ }^{b}$ Trial Identifier is the clinical trail identifier of corresponding drug.

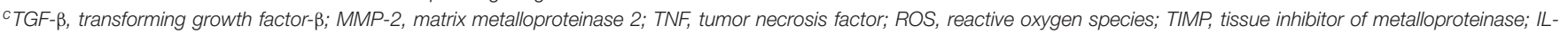

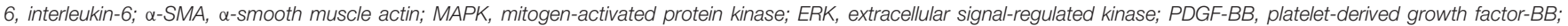

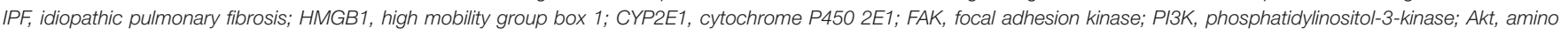

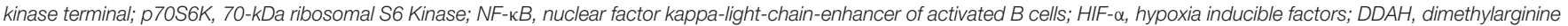
dimethylaminohydrolase; ADMA, asymmetric dimethylarginine; VEGF, vascular endothelial grow factor; BMP-7, bone morphogenetic protein 7.

more than one active ingredient. Traditional Chinese medicines (TCM) therapies, usually appeared as herbal formula, have been studied for thousands of years as multi-component drugs (Wang et al., 2012). Nowadays, single compound acting on multiple targets and multiple compounds acting on multiple targets are popular strategies in drug development (Hopkins, 2008). Fibrosis includes numerous complicated pathological pathways. Multi-component drugs, aiming at different targets, have the advantage in modulating these pathways simultaneously and producing synergistic effects. Moreover, multi-component drugs are expected to provide great resources for discovering new effective drug molecules. Many studies have revealed the pharmacology of multi-component drugs in the fibrosis treatment (Feng et al., 2009; Yang et al., 2009; Li and Kan, 2017) (Table 4). For example, Fuzhenghuayu capsule (FZHY), a well-known multi-component drug for treating liver fibrosis, inhibits liver fibrosis and improves liver function in patients via inhibition of nuclear factor kappa-B kinase subunit $\beta$ /nuclear factor $\kappa \mathrm{F}$ and TGF- $\beta$ signaling (Liu et al., 2005). Another emerging multi-component drug, Qishenyiqi (QSYQ), is under phase II clinical trial for ischemic heart failure. QSYQ attenuates cardiac fibrosis via IL-6/STAT3 and TNF- $\alpha$ /nuclear factor kappalight-chain-enhancer of activated B cells (NFKB) signalings and anti-apoptosis activities (Wang et al., 2017). Multi-component drugs act on different physiological reactions associated with fibrosis, such as inflammation and angiogenesis, leading to a systematic improvement of disease. Qushi Huayu Decoction (QHD) is a multitargeting drug that alleviates fibrosis by reducing ROS via the induction of glutathione and modulating lipid metabolism and gut barrier function (Feng et al., 2017). 
With multiple targets being discovered, it becomes apparent that more common targets will be shared across many fibrotic diseases with common mechanisms, though some proteins will not express in special conditions. Meanwhile, there will be more chance for drug repositioning, which indicate common drugs will be shared across different targets andfibroproliferative diseases.

\section{PERSPECTIVE}

Fibrosis is a common pathological process in many diseases, causing a great clinical burden in recent years. The development of state-of-the-art technologies facilitate discovery of fibrosis therapies. Multi-omics analysis provides a more convenient and systematic way for researching on disease mechanisms (Fernandes and Husi, 2017). The seamless combination of traditional transcriptomics approaches with emerging technologies, including proteomics (Ordureau et al., 2014), metabolomics (Shah et al., 2012), and metagenomics (Jiao et al., 2017), will offer unprecedented opportunities to precisely elucidating and dissecting fibrosis mechanisms. Nowadays, the application of cryo-electron microscopy (cryo-EM) in macromolecular structure determination make it easier to identify drug targets (Zheng et al., 2015). Compared with traditional X-ray crystallography, cryo-EM has advantage in determining the structure of more complex and flexible receptors (Huang et al., 2016; Zhang et al., 2017). Finally, with

\section{REFERENCES}

Akhmetshina, A., Venalis, P., Dees, C., Busch, N., Zwerina, J., Schett, G., et al. (2009). Treatment with imatinib prevents fibrosis in different preclinical models of systemic sclerosis and induces regression of established fibrosis. Arthritis Rheum. 60, 219-224. doi: 10.1002/art.24186

Alaimo, S., Giugno, R., and Pulvirenti, A. (2016). Recommendation techniques for drug-target interaction prediction and drug repositioning. Methods Mol. Biol. 1415, 441-462. doi: 10.1007/978-1-4939-3572-7_23

Ali, A. H., Carey, E. J., and Lindor, K. D. (2015). Recent advances in the development of farnesoid X receptor agonists. Ann Transl Med 3:5. doi: 10.3978/j.issn.2305-5839.2014.12.06

Alkhouri, N., Carter-Kent, C., and Feldstein, A. E. (2011). Apoptosis in nonalcoholic fatty liver disease: diagnostic and therapeutic implications. Expert Rev. Gastroenterol. Hepatol. 5, 201-212. doi: 10.1586/egh.11.6

Allen, J. T., and Spiteri, M. A. (2002). Growth factors in idiopathic pulmonary fibrosis: relative roles. Respir. Res. 3:13. doi: 10.1186/rr162

Aoyama, T., Paik, Y. H., Watanabe, S., Laleu, B., Gaggini, F., Fioraso-Cartier, L., et al. (2012). Nicotinamide adenine dinucleotide phosphate oxidase in experimental liver fibrosis: GKT137831 as a novel potential therapeutic agent. Hepatology 56, 2316-2327. doi: 10.1002/hep.25938

Apte, M. V., Pirola, R. C., and Wilson, J. S. (2012). Pancreatic stellate cells: a starring role in normal and diseased pancreas. Front. Physiol. 3:344. doi: 10.3389/fphys.2012.00344

Atkinson, J. M., Pullen, N., Da Silva-Lodge, M., Williams, L., and Johnson, T. S. (2015). Inhibition of thrombin-activated fibrinolysis inhibitor increases survival in experimental kidney fibrosis. J. Am. Soc. Nephrol. 26, 1925-1937. doi: 10.1681/ASN.2014030303

Baghdasaryan, A., Claudel, T., Gumhold, J., Silbert, D., Adorini, L., Roda, A., et al. (2011). Dual farnesoid X receptor/TGR5 agonist INT-767 reduces liver injury in the Mdr2-/- (Abcb4-/-) mouse cholangiopathy model by promoting biliary HCO(-)(3) output. Hepatology 54, 1303-1312. doi: 10.1002/hep.24537 the advent of the era of big data, artificial intelligence technology, especially deep learning, provides more accurate algorithms for drug repositioning (LeCun et al., 2015; Alaimo et al., 2016). The continuous development and application of the above technologies and methods will make it possible to identify and discover more common mechanisms, targets and drugs in fibrosis.

\section{AUTHOR CONTRIBUTIONS}

RZ and LZ conceived and designed the project. Each author has contributed significantly to the submitted work. XL drafted the manuscript. LZ, BW, MY, and RZ revised the manuscript. All authors read and approved the final manuscript.

\section{ACKNOWLEDGMENTS}

This work was supported by National Natural Science Foundation of China 31200986 (to RZ), 41530105 (to RZ), Natural Science Foundation, the Shanghai Committee of Science and Technology 16ZR1449800 (to RZ), a departmental start-up fund (to LZ), the Peter and Tommy Fund, Inc., Buffalo, NY (to LZ), and Funds from the University at Buffalo Community of Excellence in Genome, Environment and Microbiome (GEM) (to LZ). The funders had no role in study design, data collection and analysis, decision to publish, or preparation of the manuscript.

Barreyro, F. J., Holod, S., Finocchietto, P. V., Camino, A. M., Aquino, J. B., Avagnina, A., et al. (2015). The pan-caspase inhibitor Emricasan (IDN6556) decreases liver injury and fibrosis in a murine model of non-alcoholic steatohepatitis. Liver Int. 35, 953-966. doi: 10.1111/liv.12570

Biernacka, A., Dobaczewski, M., and Frangogiannis, N. G. (2011). TGF-beta signaling in fibrosis. Growth Factors 29, 196-202. doi: 10.3109/08977194.2011.595714

Block, E. T., and Cronstein, B. N. (2010). Interferon-gamma inhibits adenosine A2A receptor function in hepatic stellate cells by STAT1-mediated repression of adenylyl cyclase. Int. J. Interferon Cytokine Mediat. Res. 2010, 113-126. doi: $10.2147 /$ ijicmr.s8860

Bogatkevich, G. S., Highland, K. B., Akter, T., and Silver, R. M. (2012). The PPARgamma agonist rosiglitazone is antifibrotic for scleroderma lung fibroblasts: mechanisms of action and differential racial effects. Pulm. Med. 2012:545172. doi: 10.1155/2012/545172

Breyer, M. D., and Susztak, K. (2016). The next generation of therapeutics for chronic kidney disease. Nat. Rev. Drug Discov. 15, 568-588. doi: $10.1038 /$ nrd.2016.67

Buhling, F., Rocken, C., Brasch, F., Hartig, R., Yasuda, Y., Saftig, P., et al. (2004). Pivotal role of cathepsin K in lung fibrosis. Am. J. Pathol. 164, 2203-2216. doi: 10.1016/S0002-9440(10)63777-7

Cai, H. B., Sun, X. G., Liu, Z. F., Liu, Y. W., Tang, J., Liu, Q., et al. (2010). Effects of dahuangzhechong pills on cytokines and mitogen activated protein kinase activation in rats with hepatic fibrosis. J. Ethnopharmacol. 132, 157-164. doi: 10.1016/j.jep.2010.08.019

Caiafa, R. O., Vinuesa, A. S., Izquierdo, R. S., Brufau, B. P., Ayuso Colella, J. R., and Molina, C. N. (2013). Retroperitoneal fibrosis: role of imaging in diagnosis and follow-up. Radiographics 33, 535-552. doi: 10.1148/rg.332125085

Calleja, M. A., Vieites, J. M., Montero-Melendez, T., Torres, M. I., Faus, M. J., Gil, A., et al. (2013). The antioxidant effect of beta-caryophyllene protects rat liver from carbon tetrachloride-induced fibrosis by inhibiting hepatic stellate cell activation. Br. J. Nutr. 109, 394-401. doi: 10.1017/S0007114512001298 
Chau, B. N., Xin, C., Hartner, J., Ren, S., Castano, A. P., Linn, G., et al. (2012). MicroRNA-21 promotes fibrosis of the kidney by silencing metabolic pathways. Sci. Transl. Med. 4:121ra118. doi: 10.1126/scitranslmed.3003205

Chavez, E., Castro-Sanchez, L., Shibayama, M., Tsutsumi, V., Moreno, M. G., and Muriel, P. (2012). Sulfasalazine prevents the increase in TGF-beta, COX-2, nuclear NFkappaB translocation and fibrosis in CCl4-induced liver cirrhosis in the rat. Hum. Exp. Toxicol. 31, 913-920. doi: 10.1177/09603271124 38928

Chen, F., Wang, P. L., Fan, X. S., Yu, J. H., Zhu, Y., and Zhu, Z. H. (2016). Effect of Renshen Pingfei Decoction, a traditional Chinese prescription, on IPF induced by Bleomycin in rats and regulation of TGF-beta1/Smad3. J. Ethnopharmacol. 186, 289-297. doi: 10.1016/j.jep.2016.03.051

Chen, G., Chen, H., Wang, C., Peng, Y., Sun, L., Liu, H., et al. (2012). Rapamycin ameliorates kidney fibrosis by inhibiting the activation of mTOR signaling in interstitial macrophages and myofibroblasts. PLOS ONE 7:e33626. doi: 10.1371/journal.pone.0033626

Chen, S. J., Yuan, W., Mori, Y., Levenson, A., Trojanowska, M., and Varga, J. (1999). Stimulation of type I collagen transcription in human skin fibroblasts by TGF-beta: involvement of Smad 3. J. Invest. Dermatol. 112, 49-57. doi: 10.1046/j.1523-1747.1999.00477.x

Chen, Y., Yang, S., Yao, W., Zhu, H., Xu, X., Meng, G., et al. (2014). Prostacyclin analogue beraprost inhibits cardiac fibroblast proliferation depending on prostacyclin receptor activation through a TGF beta-Smad signal pathway. PLoS ONE 9:e98483. doi: 10.1371/journal.pone.0098483

Cheresh, P., Kim, S. J., Tulasiram, S., and Kamp, D. W. (2013). Oxidative stress and pulmonary fibrosis. Biochim. Biophys. Acta 1832, 1028-1040. doi: 10.1016/j.bbadis.2012.11.021

Chiu, Y. W., Chao, P. Y., Tsai, C. C., Chiou, H. L., Liu, Y. C., Hung, C. C., et al. (2014). Ocimum gratissimum is effective in prevention against liver fibrosis in vivo and in vitro. Am. J. Chin. Med. 42, 833-852. doi: 10.1142/S0192415X14500530

Choi, K., Lee, K., Ryu, S. W., Im, M., Kook, K. H., and Choi, C. (2012). Pirfenidone inhibits transforming growth factor-betal-induced fibrogenesis by blocking nuclear translocation of Smads in human retinal pigment epithelial cell line ARPE-19. Mol. Vis. 18, 1010-1020.

Corbel, M., Caulet-Maugendre, S., Germain, N., Molet, S., Lagente, V., and Boichot, E. (2001). Inhibition of bleomycin-induced pulmonary fibrosis in mice by the matrix metalloproteinase inhibitor batimastat. J. Pathol. 193, 538-545. doi: $10.1002 /$ path. 826

Couluris, M., Kinder, B. W., Xu, P., Gross-King, M., Krischer, J., and Panos, R. J. (2012). Treatment of idiopathic pulmonary fibrosis with losartan: a pilot project. Lung 190, 523-527. doi: 10.1007/s00408-012-9410-Z

Cui, W., Li, L., Li, D., Mo, X., Zhou, W., Zhang, Z., et al. (2015). Total glycosides of Yupingfeng protects against bleomycin-induced pulmonary fibrosis in rats associated with reduced high mobility group box 1 activation and epithelial-mesenchymal transition. Inflamm. Res. 64, 953-961. doi: 10.1007/s00011-015-0878-x

Daniels, C. E., Lasky, J. A., Limper, A. H., Mieras, K., Gabor, E., Schroeder, D. R., et al. (2010). Imatinib treatment for idiopathic pulmonary fibrosis: randomized placebo-controlled trial results. Am. J. Respir. Crit. Care Med. 181, 604-610. doi: 10.1164/rccm.200906-0964OC

de Meijer, V. E., Sverdlov, D. Y., Popov, Y., Le, H. D., Meisel, J. A., Nose, V., et al. (2010). Broad-spectrum matrix metalloproteinase inhibition curbs inflammation and liver injury but aggravates experimental liver fibrosis in mice. PLoS ONE 5:e11256. doi: 10.1371/journal.pone.0011256

De Minicis, S., Marzioni, M., Saccomanno, S., Rychlicki, C., Agostinelli, L., Trozzi, L., et al. (2012). Cellular and molecular mechanisms of hepatic fibrogenesis leading to liver cancer. Transl. Gastrointest. Cancer 1, 88-94. doi: 10.3978/j.issn.2224-4778.2011.12.05

Deger, Y., Yur, F., Ertekin, A., Mert, N., Dede, S., and Mert, H. (2007). Protective effect of alpha-tocopherol on oxidative stress in experimental pulmonary fibrosis in rats. Cell Biochem. Funct. 25, 633-637. doi: 10.1002/cbf.1362

Demedts, M., Behr, J., Buhl, R., Costabel, U., Dekhuijzen, R., Jansen, H. M., et al. (2005). High-dose acetylcysteine in idiopathic pulmonary fibrosis. N. Engl. J. Med. 353, 2229-2242. doi: 10.1056/NEJMoa042976

Depner, C. M., Philbrick, K. A., and Jump, D. B. (2013). Docosahexaenoic acid attenuates hepatic inflammation, oxidative stress, and fibrosis without decreasing hepatosteatosis in a Ldlr(-/-) mouse model of western diet-induced nonalcoholic steatohepatitis. J. Nutr. 143, 315-323. doi: 10.3945/jn.112.171322.

Ding, J., Yu, J., Wang, C., Hu, W., Li, D., Luo, Y., et al. (2005). Ginkgo biloba extract alleviates liver fibrosis induced by $\mathrm{CCl}$ in rats. Liver Int. 25, 1224-1232. doi: 10.1111/j.1478-3231.2005.01169.x

Dinwiddie, R. (2005). Anti-inflammatory therapy in cystic fibrosis. J. Cyst. Fibros 4(Suppl. 2), 45-48. doi: 10.1016/j.jcf.2005.05.010

Dong, D., Yin, L., Qi, Y., Xu, L., and Peng, J. (2015). Protective effect of the total saponins from Rosa laevigata michx fruit against carbon tetrachloride-induced liver fibrosis in rats. Nutrients 7, 4829-4850. doi: 10.3390/nu7064829

Ezquerro, I. J., Lasarte, J. J., Dotor, J., Castilla-Cortazar, I., Bustos, M., Penuelas, I., et al. (2003). A synthetic peptide from transforming growth factor $\beta$ type III receptor inhibits liver fibrogenesis in rats with carbon tetrachloride liver injury. Cytokine 22, 12-20. doi: 10.1016/s1043-4666(03)00101-7

Fallowfield, J. A. (2011). Therapeutic targets in liver fibrosis. Am. J. Physiol. Gastrointest. Liver Physiol. 300, G709-G715. doi: 10.1152/ajpgi.00451.2010

Fan, G. P., Wang, W., Zhao, H., Cai, L., Zhang, P. D., Yang, Z. H., et al. (2015). Pharmacological inhibition of focal adhesion kinase attenuates cardiac fibrosis in mice cardiac fibroblast and post-myocardial-infarction models. Cell. Physiol. Biochem. 37, 515-526. doi: 10.1159/000430373

Feng, Q., Liu, W., Baker, S. S., Li, H., Chen, C., Liu, Q., et al. (2017). Multitargeting therapeutic mechanisms of the Chinese herbal medicine QHD in the treatment of non-alcoholic fatty liver disease. Oncotarget 8, 27820-27838. doi: 10.18632/oncotarget.15482

Feng, Y., Cheung, K. F., Wang, N., Liu, P., Nagamatsu, T., and Tong, Y. (2009). Chinese medicines as a resource for liver fibrosis treatment. Chin. Med. 4:16. doi: 10.1186/1749-8546-4-16

Fernandes, M., and Husi, H. (2017). Establishment of a integrative multi-omics expression database CKDdb in the context of chronic kidney disease (CKD). Sci. Rep. 7:40367. doi: 10.1038/srep40367

Fielding, C. A., Jones, G. W., McLoughlin, R. M., McLeod, L., Hammond, V. J., Uceda, J., et al. (2014). Interleukin-6 signaling drives fibrosis in unresolved inflammation. Immunity 40, 40-50. doi: 10.1016/j.immuni.2013.10.022

Fine, A., and Goldstein, R. H. (1987). The effect of transforming growth factor-beta on cell proliferation and collagen formation by lung fibroblasts. J. Biol. Chem. 262, 3897-3902.

Fiorucci, S., Antonelli, E., Distrutti, E., Severino, B., Fiorentina, R., Baldoni, M., et al. (2004). PAR1 antagonism protects against experimental liver fibrosis. Role of proteinase receptors in stellate cell activation. Hepatology 39, 365-375. doi: 10.1002/hep.20054

Fukumori, T., Takenaka, Y., Yoshii, T., Kim, H. R., Hogan, V., Inohara, H., et al. (2003). CD29 and CD7 mediate galectin-3-induced type II T-cell apoptosis. Cancer Res. 63, 8302-8311.

Gao, Y., Lu, J., Zhang, Y., Chen, Y., Gu, Z., and Jiang, X. (2013). Baicalein attenuates bleomycin-induced pulmonary fibrosis in rats through inhibition of miR-21. Pulm. Pharmacol. Ther. 26, 649-654. doi: 10.1016/j.pupt.2013.03.006

Gao, Y., Yao, L. F., Zhao, Y., Wei, L. M., Guo, P., Yu, M., et al. (2016). The chinese herbal medicine formula $\mathrm{mKG}$ suppresses pulmonary fibrosis of mice induced by bleomycin. Int. J. Mol. Sci. 17:238. doi: 10.3390/ijms17020238

Ghosh, A. K., Bhattacharyya, S., Wei, J., Kim, S., Barak, Y., Mori, Y., et al. (2009). Peroxisome proliferator-activated receptor-gamma abrogates Smad-dependent collagen stimulation by targeting the $\mathrm{p} 300$ transcriptional coactivator. FASEB J. 23, 2968-2977. doi: 10.1096/fj.08-128736

Giannandrea, M., and Parks, W. C. (2014). Diverse functions of matrix metalloproteinases during fibrosis. Dis. Model. Mech. 7, 193-203. doi: 10.1242/dmm.012062

Gill, S. E., Huizar, I., Bench, E. M., Sussman, S. W., Wang, Y., Khokha, R., et al. (2010). Tissue inhibitor of metalloproteinases 3 regulates resolution of inflammation following acute lung injury. Am. J. Pathol. 176, 64-73. doi: 10.2353/ajpath.2010.090158

Gomez-Arroyo, J., Sakagami, M., Syed, A. A., Farkas, L., Van Tassell, B., Kraskauskas, D., et al. (2015). Iloprost reverses established fibrosis in experimental right ventricular failure. Eur. Respir. J. 45, 449-462. doi: 10.1183/09031936.00188013

Gonzalez, E. O., Boix, V., Deltoro, M. G., Aldeguer, J. L., Portilla, J., Montero, M., et al. (2014). The effects of Maraviroc on liver fibrosis in HIV/HCV co-infected patients. J. Int. AIDS Soc. 17(4 Suppl. 3):19643. doi: 10.7448/IAS.17.4.19643 
Gu, L., Tao, X., Xu, Y., Han, X., Qi, Y., Xu, L., et al. (2016). Dioscin alleviates BDL- and DMN-induced hepatic fibrosis via Sirt1/Nrf2-mediated inhibition of p38 MAPK pathway. Toxicol. Appl. Pharmacol. 292, 19-29. doi: $10.1016 /$ j.taap.2015.12.024

Gulati, A., Jabbour, A., Ismail, T. F., Guha, K., Khwaja, J., Raza, S., et al. (2013). Association of fibrosis with mortality and sudden cardiac death in patients with nonischemic dilated cardiomyopathy. JAMA 309, 896-908. doi: 10.1001/jama.2013.1363

Hashimoto, S., Gon, Y., Takeshita, I., Maruoka, S., and Horie, T. (2001). IL-4 and IL-13 induce myofibroblastic phenotype of human lung fibroblasts through c-Jun NH2-terminal kinase-dependent pathway. J. Allergy Clin. Immunol. 107, 1001-1008. doi: 10.1067/mai.2001. 114702

He, W., Dai, C., Li, Y., Zeng, G., Monga, S. P., and Liu, Y. (2009). Wnt/beta-catenin signaling promotes renal interstitial fibrosis. J. Am. Soc. Nephrol. 20, 765-776. doi: 10.1681/ASN.2008060566

Henderson, N. C., Arnold, T. D., Katamura, Y., Giacomini, M. M., Rodriguez, J. D., McCarty, J. H., et al. (2013). Selective $\alpha v$ integrin depletion identifies a core, targetable molecular pathway that regulates fibrosis across solid organs. Nat. Med. 19, 1617-1624. doi: 10.1038/nm.3282

Hinz, B., Phan, S. H., Thannickal, V. J., Galli, A., Bochaton-Piallat, M. L., and Gabbiani, G. (2007). The myofibroblast: one function, multiple origins. Am. J. Pathol. 170, 1807-1816. doi: 10.2353/ajpath.2007.070112

Hopkins, A. L. (2008). Network pharmacology: the next paradigm in drug discovery. Nat. Chem. Biol. 4, 682-690. doi: 10.1038/nchembio.118

Horton, M. R., Santopietro, V., Mathew, L., Horton, K. M., Polito, A. J., Liu, M. C., et al. (2012). Thalidomide for the treatment of cough in idiopathic pulmonary fibrosis: a randomized trial. Ann. Intern. Med. 157, 398-406. doi: 10.7326/0003-4819-157-6-201209180-00003

Hou, F., Liu, R., Liu, X., Cui, L., Wen, Y., Yan, S., et al. (2016). Attenuation of liver fibrosis by herbal compound 861 via upregulation of BMP-7/Smad signaling in the bile duct ligation model rat. Mol. Med. Rep. 13, 4335-4342. doi: $10.3892 / \mathrm{mmr} .2016 .5071$

Huan, C., Yang, T., Liang, J., Xie, T., Cheng, L., Liu, N., et al. (2015). Methylationmediated BMPER expression in fibroblast activation in vitro and lung fibrosis in mice in vivo. Sci. Rep. 5:14910. doi: 10.1038/srep14910

Huang, X., Luan, B., Wu, J., and Shi, Y. (2016). An atomic structure of the human 26 S proteasome. Nat. Struct. Mol. Biol. 23, 778-785. doi: 10.1038/nsmb.3273

Hutchinson, J., Fogarty, A., Hubbard, R., and McKeever, T. (2015). Global incidence and mortality of idiopathic pulmonary fibrosis: a systematic review. Eur. Respir. J. 46, 795-806. doi: 10.1183/09031936.00185114

Huuskes, B. M., Wise, A. F., Cox, A. J., Lim, E. X., Payne, N. L., Kelly, D. J., et al. (2015). Combination therapy of mesenchymal stem cells and serelaxin effectively attenuates renal fibrosis in obstructive nephropathy. FASEB J. 29, 540-553. doi: 10.1096/fj.14-254789

Iannitti, R. G., Napolioni, V., Oikonomou, V., De Luca, A., Galosi, C., Pariano, M., et al. (2016). IL-1 receptor antagonist ameliorates inflammasome-dependent inflammation in murine and human cystic fibrosis. Nat. Commun. 7:10791. doi: 10.1038/ncomms10791

Imai, K., and Takaoka, A. (2006). Comparing antibody and small-molecule therapies for cancer. Nat. Rev. Cancer 6, 714-727. doi: 10.1038/nrc1913

Jacobson, G., Bhatia, S., Smith, B. J., Button, A. M., Bodeker, K., and Buatti, J. (2013). Randomized trial of pentoxifylline and vitamin E vs standard follow-up after breast irradiation to prevent breast fibrosis, evaluated by tissue compliance meter. Int. J. Radiat. Oncol. Biol. Phys. 85, 604-608. doi: 10.1016/j.ijrobp.2012.06.042

Jiao, N., Baker, S. S., Chapa-Rodriguez, A., Liu, W., Nugent, C. A., Tsompana, M., et al. (2017). Suppressed hepatic bile acid signalling despite elevated production of primary and secondary bile acids in NAFLD. Gut. doi: 10.1136/gutjnl-2017-314307. [Epub ahead of print].

Jirouskova, M., Zbodakova, O., Gregor, M., Chalupsky, K., Sarnova, L., Hajduch, M., et al. (2012). Hepatoprotective effect of MMP-19 deficiency in a mouse model of chronic liver fibrosis. PLoS ONE 7:e46271. doi: 10.1371/journal.pone.0046271

Johnson, T. S., Fisher, M., Haylor, J. L., Hau, Z., Skill, N. J., Jones, R., et al. (2007). Transglutaminase inhibition reduces fibrosis and preserves function in experimental chronic kidney disease. J. Am. Soc. Nephrol. 18, 3078-3088. doi: 10.1681/ASN.2006070690
Kaneshige, T., Saida, Y., Tanaka, R., Soda, A., Fukushima, A., Ida, N., et al. (2007). Effect of long-term administration of a prostacyclin analogue (beraprost sodium) on myocardial fibrosis in Dahl rats. J. Vet. Med. Sci. 69, 1271-1276. doi: 10.1292/jvms.69.1271

Kawano, H., Kimura-Kuroda, J., Komuta, Y., Yoshioka, N., Li, H. P., Kawamura, K., et al. (2012). Role of the lesion scar in the response to damage and repair of the central nervous system. Cell Tissue Res. 349, 169-180. doi: 10.1007/s00441-012-1336-5

Khan, R., and Sheppard, R. (2006). Fibrosis in heart disease: understanding the role of transforming growth factor-beta in cardiomyopathy, valvular disease and arrhythmia. Immunology 118, 10-24. doi: 10.1111/j.1365-2567.2006.02336.x

Khanna, D., Albera, C., Fischer, A., Khalidi, N., Raghu, G., Chung, L., et al. (2016). An Open-label, phase II study of the safety and tolerability of pirfenidone in patients with scleroderma-associated interstitial Lung Disease: the LOTUSS trial. J. Rheumatol. 43, 1672-1679. doi: 10.3899/jrheum.151322

Khanna, D., Saggar, R., Mayes, M. D., Abtin, F., Clements, P. J., Maranian, P., et al. (2011). A one-year, phase I/IIa, open-label pilot trial of imatinib mesylate in the treatment of systemic sclerosis-associated active interstitial lung disease. Arthritis Rheum. 63, 3540-3546. doi: 10.1002/art.30548

Kim, D., Kim, W. R., Kim, H. J., and Therneau, T. M. (2013). Association between noninvasive fibrosis markers and mortality among adults with nonalcoholic fatty liver disease in the United States. Hepatology 57, 1357-1365. doi: 10.1002/hep.26156

Kim, L., Kim, D. K., Yang, W. I., Shin, D. H., Jung, I. M., Park, H. K., et al. (2008). Overexpression of transforming growth factor-beta 1 in the valvular fibrosis of chronic rheumatic heart disease. J. Korean Med. Sci. 23, 41-48. doi: $10.3346 / \mathrm{jkms} .2008 .23 .1 .41$

King, T. E. Jr., Bradford, W. Z., Castro-Bernardini, S., Fagan, E. A., Glaspole, I., Glassberg, M. K., et al. (2014). A phase 3 trial of pirfenidone in patients with idiopathic pulmonary fibrosis. N. Engl. J. Med. 370, 2083-2092. doi: 10.1056/NEJMoa1402582

Kitagawa, K., Wada, T., Furuichi, K., Hashimoto, H., Ishiwata, Y., Asano, M., et al. (2004). Blockade of CCR2 ameliorates progressive fibrosis in kidney. Am. J. Pathol. 165, 237-246. doi: 10.1016/S0002-9440(10)63292-0

Koh, R. Y., Lim, C. L., Uhal, B. D., Abdullah, M., Vidyadaran, S., Ho, C. C., et al. (2015). Inhibition of transforming growth factor-beta via the activin receptor-like kinase- 5 inhibitor attenuates pulmonary fibrosis. Mol. Med. Rep. 11, 3808-3813. doi: 10.3892/mmr.2015.3193

Kuwano, K., Kunitake, R., Maeyama, T., Hagimoto, N., Kawasaki, M., Matsuba, T., et al. (2001). Attenuation of bleomycin-induced pneumopathy in mice by a caspase inhibitor. Am. J. Physiol. Lung Cell. Mol. Physiol. 280, L316-L325.

Lagares, D., Busnadiego, O., Garcia-Fernandez, R. A., Kapoor, M., Liu, S., Carter, D. E., et al. (2012). Inhibition of focal adhesion kinase prevents experimental lung fibrosis and myofibroblast formation. Arthritis Rheum. 64, 1653-1664. doi: $10.1002 /$ art. 33482

Lan, H. Y. (2011). Diverse roles of TGF- $\beta /$ Smads in renal fibrosis and inflammation. Int. J. Biol. Sci. 7, 1056-1067. doi: 10.7150/ijbs.7.1056

Lawrance, I. C., Wu, F., Leite, A. Z., Willis, J., West, G. A., Fiocchi, C., et al. (2003). A murine model of chronic inflammation-induced intestinal fibrosis down-regulated by antisense NF-кB. Gastroenterology 125, 1750-1761. doi: 10.1053/j.gastro.2003.08.027

LeCun, Y., Bengio, Y., and Hinton, G. (2015). Deep learning. Nature 521, 436-444. doi: 10.1038/nature14539

Lerch, M. M., and Halangk, W. (2006). Human pancreatitis and the role of cathepsin B. Gut 55, 1228-1230. doi: 10.1136/gut.2006.092114

Li, B., and Wang, J. H. (2011). Fibroblasts and myofibroblasts in wound healing: force generation and measurement. J. Tissue Viability 20, 108-120. doi: 10.1016/j.jtv.2009.11.004

Li, C. H., Pan, L. H., Yang, Z. W., Li, C. Y., and Xu, W. X. (2008). Preventive effect of Qianggan-Rongxian Decoction on rat liver fibrosis. World J. Gastroenterol. 14, 3569-3573. doi: 10.3748/wjg.14.3569

Li, C. X., Li, L., Lou, J., Yang, W. X., Lei, T. W., Li, Y. H., et al. (1998). The protective effects of traditional Chinese medicine prescription, han-dan-ganle, on CCl4-induced liver fibrosis in rats. Am. J. Chin. Med. 26, 325-332. doi: $10.1142 /$ S0192415X98000361

Li, L. C., and Kan, L. D. (2017). Traditional Chinese medicine for pulmonary fibrosis therapy: progress and future prospects. J. Ethnopharmacol. 198, 45-63. doi: 10.1016/j.jep.2016.12.042 
Li, L. C., Li, J., and Gao, J. (2014). Functions of galectin-3 and its role in fibrotic diseases. J. Pharmacol. Exp. Ther. 351, 336-343. doi: 10.1124/jpet.114.218370

Lin, J., Zhu, X., Chade, A. R., Jordan, K. L., Lavi, R., Daghini, E., et al. (2009). Monocyte chemoattractant proteins mediate myocardial microvascular dysfunction in swine renovascular hypertension. Arterioscler. Thromb. Vasc. Biol. 29, 1810-1816. doi: 10.1161/ATVBAHA.109. 190546

Liu, A., Gao, X., Zhang, Q., and Cui, L. (2013). Cathepsin B inhibition attenuates cardiac dysfunction and remodeling following myocardial infarction by inhibiting the NLRP3 pathway. Mol. Med. Rep. 8, 361-366. doi: $10.3892 / \mathrm{mmr} .2013 .1507$

Liu, G., Friggeri, A., Yang, Y., Milosevic, J., Ding, Q., Thannickal, V. J., et al. (2010). miR-21 mediates fibrogenic activation of pulmonary fibroblasts and lung fibrosis. J. Exp. Med. 207, 1589-1597. doi: 10.1084/jem.20100035

Liu, H., Dong, F., Li, G., Niu, M., Zhang, C., Han, Y., et al. (2017). Liuweiwuling tablets attenuate BDL-induced hepatic fibrosis via modulation of TGFbeta/Smad and NF-kappaB signaling pathways. J. Ethnopharmacol. 210, 232-241. doi: 10.1016/j.jep.2017.08.029

Liu, M., Xu, Y., Han, X., Yin, L., Xu, L., Qi, Y., et al. (2015). Dioscin alleviates alcoholic liver fibrosis by attenuating hepatic stellate cell activation via the TLR4/MyD88/NF-kappaB signaling pathway. Sci. Rep. 5:18038. doi: $10.1038 /$ srep 18038

Liu, P., Hu, Y. Y., Liu, C., Xu, L. M., Liu, C. H., Sun, K. W., et al. (2005). Multicenter clinical study on Fuzhenghuayu capsule against liver fibrosis due to chronic hepatitis B. World J. Gastroenterol. 11, 2892-2899. doi: 10.3748/wjg.v11.i19.2892

Liu, P., Hu, Y. Y., Liu, C., Zhu, D. Y., Xue, H. M., Xu, Z. Q., et al. (2002). Clinical observation of salvianolic acid B in treatment of liver fibrosis in chronic hepatitis B. World J. Gastroenterol. 8, 679-685. doi: 10.3748/wjg.v8.i4.679

Liu, Q., Chu, H., Ma, Y., Wu, T., Qian, F., Ren, X., et al. (2016). Salvianolic acid B attenuates experimental pulmonary fibrosis through inhibition of the TGF-beta signaling pathway. Sci. Rep. 6:27610. doi: 10.1038/srep27610

Liu, Y., Binz, J., Numerick, M. J., Dennis, S., Luo, G., Desai, B., et al. (2003). Hepatoprotection by the farnesoid X receptor agonist GW4064 in rat models of intra- and extrahepatic cholestasis. J. Clin. Invest. 112, 1678-1687. doi: 10.1172/JCI18945

Lu, X. D., Pang, L. J., Wang, L. L., Nan, M. H., and Ma, Z. (2010). Effects of Chinese herbal medicine Shenlong Decoction on mRNA expressions of matrix metalloproteinase-2 and tissue inhibitor of metalloproteinase-1 in lung tissue of rats with pulmonary fibrosis induced by bleomycin. Zhong Xi Yi Jie He Xue Bao 8, 961-967. doi: 10.3736/jcim20101008

Lv, J., Zhao, Z., Chen, Y., Wang, Q., Tao, Y., Yang, L., et al. (2012). The chinese herbal decoction danggui buxue tang inhibits angiogenesis in a rat model of liver fibrosis. Evid. Based Complement. Alternat. Med. 2012:284963. doi: $10.1155 / 2012 / 284963$

Mahmoud, M. F., Swefy, S. E., Hasan, R. A., and Ibrahim, A. (2014). Role of cannabinoid receptors in hepatic fibrosis and apoptosis associated with bile duct ligation in rats. Eur. J. Pharmacol. 742, 118-124. doi: 10.1016/j.ejphar.2014.08.021

Makarev, E., Izumchenko, E., Aihara, F., Wysocki, P. T., Zhu, Q., Buzdin, A., et al. (2016). Common pathway signature in lung and liver fibrosis. Cell Cycle 15, 1667-1673. doi: 10.1080/15384101.2016.1152435

Maldonado, F., Kottom, T., and Limper, A. (2009). PXS-25, a Mannose-6phosphate derivative, is effective in decreasing the production of extracellular matrix by TGF-beta stimulated fibroblasts. Am. Thoracic. Soc. 179:A3471. doi: 10.1164/ajrccm-conference.2009.179.1

Manitsopoulos, N., Kotanidou, A., Magkou, C., Ninou, I., Tian, X., Aidinis, V., et al. (2015). Treprostinil administration attenuates bleomycin-induced lung fibrosis in mice. Eur. Respir. Soc.. 46:PA3837. doi: 10.1183/13993003.congress-2015.PA3837

Martinez-Martinez, E., Rodriguez, C., Galan, M., Miana, M., Jurado-Lopez, R., Bartolome, M. V., et al. (2016). The lysyl oxidase inhibitor (betaaminopropionitrile) reduces leptin profibrotic effects and ameliorates cardiovascular remodeling in diet-induced obesity in rats. J. Mol. Cell. Cardiol. 92, 96-104. doi: 10.1016/j.yjmcc.2016.01.012

Mathioudakis, A., Chatzimavridou-Grigoriadou, V., Evangelopoulou, E., and Mathioudakis, G. (2013). Vasoactive intestinal Peptide inhaled agonists: potential role in respiratory therapeutics. Hippokratia 17, 12-16.
Matsumura, Y., Sakaida, I., Uchida, K., Kimura, T., Ishihara, T., and Okita, K. (1997). Prolyl 4-hydroxylase inhibitor (HOE 077) inhibits pig serum-induced rat liver fibrosis by preventing stellate cell activation. J. Hepatol. 27, 185-192.

Meng, X. M., Nikolic-Paterson, D. J., and Lan, H. Y. (2016). TGFbeta: the master regulator of fibrosis. Nat. Rev. Nephrol. 12, 325-338. doi: 10.1038/nrneph.2016.48

Meng, X. M., Tang, P. M., Li, J., and Lan, H. Y. (2015). TGF-beta/Smad signaling in renal fibrosis. Front. Physiol. 6:82. doi: 10.3389/fphys.2015.00082

Mitragotri, S., Burke, P. A., and Langer, R. (2014). Overcoming the challenges in administering biopharmaceuticals: formulation and delivery strategies. Nat. Rev. Drug Discov. 13, 655-672. doi: 10.1038/nrd4363

Moreira, R. K. (2007). Hepatic stellate cells and liver fibrosis. Arch. Pathol. Lab. Med. 131, 1728-1734. doi: 10.1043/1543-2165(2007)131[1728\%3AHSCALF]2. $0 . \mathrm{CO} \% 3 \mathrm{~B} 2$

Moss, R. B., Mayer-Hamblett, N., Wagener, J., Daines, C., Hale, K., Ahrens, R., et al. (2005). Randomized, double-blind, placebo-controlled, dose-escalating study of aerosolized interferon gamma- $1 \mathrm{~b}$ in patients with mild to moderate cystic fibrosis lung disease. Pediatr. Pulmonol. 39, 209-218. doi: 10.1002/ppul.20152

Muir, A. J., Sylvestre, P. B., and Rockey, D. C. (2006). Interferon gamma-1b for the treatment of fibrosis in chronic hepatitis C infection. J. Viral Hepat. 13, 322-328. doi: 10.1111/j.1365-2893.2005.00689.x

Murray, L. A., Zhang, H., Oak, S. R., Coelho, A. L., Herath, A., Flaherty, K. R., et al. (2014). Targeting interleukin-13 with tralokinumab attenuates lung fibrosis and epithelial damage in a humanized SCID idiopathic pulmonary fibrosis model. Am. J. Respir. Cell Mol. Biol. 50, 985-994. doi: 10.1165/rcmb.2013-0342OC

Nadadur, R., Umar, S., Matori, H., Iorga, A., Mai, D., Amjedi, M., et al. (2012). Genistein therapy reverses lung inflammation and fibrosis during severe pulmonary hypertension through estrogen receptor beta. Biophys. J. 102:140a. doi: 10.1016/j.bpj.2011.11.772

Okunieff, P., Augustine, E., Hicks, J. E., Cornelison, T. L., Altemus, R. M., Naydich, B. G., et al. (2004). Pentoxifylline in the treatment of radiation-induced fibrosis. J. Clin. Oncol. 22, 2207-2213. doi: 10.1200/JCO.2004.09.101

Omenetti, A., Porrello, A., Jung, Y., Yang, L., Popov, Y., Choi, S. S., et al. (2008). Hedgehog signaling regulates epithelial-mesenchymal transition during biliary fibrosis in rodents and humans. J. Clin. Invest. 118, 3331-3342. doi: $10.1172 / \mathrm{JCI} 35875$

Ordureau, A., Sarraf, S. A., Duda, D. M., Heo, J. M., Jedrychowski, M. P., Sviderskiy, V. O., et al. (2014). Quantitative proteomics reveal a feedforward mechanism for mitochondrial PARKIN translocation and ubiquitin chain synthesis. Mol. Cell 56, 360-375. doi: 10.1016/j.molcel.2014.09.007

Overington, J. P., Al-Lazikani, B., and Hopkins, A. L. (2006). How many drug targets are there? Nat. Rev. Drug Discov. 5, 993-996. doi: 10.1038/nrd2199

Pan, R. H., Xie, F. Y., Chen, H. M., Xu, L. Z., Wu, X. C., Xu, L. L., et al. (2011). Salvianolic acid B reverses the epithelial-to-mesenchymal transition of HK-2 cells that is induced by transforming growth factor-beta. Arch. Pharm. Res. 34, 477-483. doi: 10.1007/s12272-011-0317-7

Parish, J. M., and Rosenow, E. C. III. (2002). Mediastinal granuloma and mediastinal fibrosis. Semin. Respir. Crit. Care Med. 23, 135-143. doi: $10.1055 / \mathrm{s}-2002-25302$

Peinado, H., Del Carmen Iglesias-de la Cruz, M., Olmeda, D., Csiszar, K., Fong, K. S., Vega, S., et al. (2005). A molecular role for lysyl oxidase-like 2 enzyme in snail regulation and tumor progression. EMBO J. 24, 3446-3458. doi: 10.1038/sj.emboj.7600781

Pellicoro, A., Ramachandran, P., Iredale, J. P., and Fallowfield, J. A. (2014). Liver fibrosis and repair: immune regulation of wound healing in a solid organ. Nat. Rev. Immunol. 14, 181-194. doi: 10.1038/nri3623

Radbill, B. D., Gupta, R., Ramirez, M. C., DiFeo, A., Martignetti, J. A., Alvarez, C. E., et al. (2011). Loss of matrix metalloproteinase-2 amplifies murine toxininduced liver fibrosis by upregulating collagen I expression. Dig. Dis. Sci. 56, 406-416. doi: 10.1007/s10620-010-1296-0

Raghu, G., Brown, K. K., Costabel, U., Cottin, V., du Bois, R. M., Lasky, J. A., et al. (2008). Treatment of idiopathic pulmonary fibrosis with etanercept: an exploratory, placebo-controlled trial. Am. J. Respir. Crit. Care Med. 178, 948-955. doi: 10.1164/rccm.200709-1446OC

Raghu, G., Chen, S. Y., Yeh, W. S., Maroni, B., Li, Q., Lee, Y. C., et al. (2014). Idiopathic pulmonary fibrosis in US Medicare beneficiaries aged 65 years and older: incidence, prevalence, and survival, 2001-11. Lancet Respir Med 2, 566-572. doi: 10.1016/S2213-2600(14)70101-8 
Raimundo, K., Chang, E., Broder, M. S., Alexander, K., Zazzali, J., and Swigris, J. J. (2016). Clinical and economic burden of idiopathic pulmonary fibrosis: a retrospective cohort study. BMC Pulm. Med. 16:2. doi: 10.1186/s12890-015-0165-1

Redente, E. F., Keith, R. C., Janssen, W., Henson, P. M., Ortiz, L. A., Downey, G. P., et al. (2014). Tumor necrosis factor-alpha accelerates the resolution of established pulmonary fibrosis in mice by targeting profibrotic lung macrophages. Am. J. Respir. Cell Mol. Biol. 50, 825-837. doi: 10.1165/rcmb.2013-0386OC

Reif, S., Lang, A., Lindquist, J. N., Yata, Y., Gabele, E., Scanga, A., et al. (2003). The role of focal adhesion kinase-phosphatidylinositol 3-kinase-akt signaling in hepatic stellate cell proliferation and type I collagen expression. J. Biol. Chem. 278, 8083-8090. doi: 10.1074/jbc.M212927200

Reiter, T., Ritter, O., Prince, M. R., Nordbeck, P., Wanner, C., Nagel, E., et al. (2012). Minimizing risk of nephrogenic systemic fibrosis in cardiovascular magnetic resonance. J. Cardiovasc. Magn. Reson. 14:31. doi: 10.1186/1532-429X14-31

Ritter, C., Zhang, S., Finch, J. L., Liapis, H., Suarez, E., Ferder, L., et al. (2014). Cardiac and renal effects of atrasentan in combination with enalapril and paricalcitol in uremic rats. Kidney Blood Press. Res. 39, 340-352. doi: 10.1159/000355811

Rockey, D. C., Bell, P. D., and Hill, J. A. (2015). Fibrosis-a common pathway to organ injury and failure. N. Engl. J. Med. 372, 1138-1149. doi: 10.1056/NEJMra1300575

Salas, A. L., Montezuma, T. D., Farina, G. G., Reyes-Esparza, J., and RodriguezFragoso, L. (2008). Genistein modifies liver fibrosis and improves liver function by inducing uPA expression and proteolytic activity in CCl4-treated rats. Pharmacology 81, 41-49. doi: 10.1159/000107968

Samad, M. A., Kim, U. K., Kang, J. J., Ke, Q., and Kang, P. M. (2015). Endothelin A receptor antagonist, atrasentan, attenuates renal and cardiac dysfunction in Dahl salt-hypertensive rats in a blood pressure independent manner. PLoS ONE 10:e0121664. doi: 10.1371/journal.pone.0121664

Samuel, C. S., Bodaragama, H., Chew, J. Y., Widdop, R. E., Royce, S. G., and Hewitson, T. D. (2014). Serelaxin is a more efficacious antifibrotic than enalapril in an experimental model of heart disease. Hypertension 64, 315-322. doi: 10.1161/HYPERTENSIONAHA.114.03594

Sangaralingham, S. J., Wang, B. H., Huang, L., Kumfu, S., Ichiki, T., Krum, H., et al. (2016). Cardiorenal fibrosis and dysfunction in aging: imbalance in mediators and regulators of collagen. Peptides 76, 108-114. doi: 10.1016/j.peptides.2016.01.004

Sawant, K. V., Poluri, K. M., Dutta, A. K., Sepuru, K. M., Troshkina, A., Garofalo, R. P., et al. (2016). Chemokine CXCL1 mediated neutrophil recruitment: role of glycosaminoglycan interactions. Sci. Rep. 6:33123. doi: 10.1038/srep33123

Sebe, A., Leivonen, S. K., Fintha, A., Masszi, A., Rosivall, L., Kahari, V. M., et al. (2008). Transforming growth factor-beta-induced alphasmooth muscle cell actin expression in renal proximal tubular cells is regulated by p38beta mitogen-activated protein kinase, extracellular signalregulated protein kinase1,2 and the Smad signalling during epithelialmyofibroblast transdifferentiation. Nephrol. Dial. Transplant 23, 1537-1545. doi: $10.1093 / \mathrm{ndt} / \mathrm{gfm} 789$

Seki, E., De Minicis, S., Gwak, G. Y., Kluwe, J., Inokuchi, S., Bursill, C. A., et al. (2009). CCR1 and CCR5 promote hepatic fibrosis in mice. J. Clin. Invest. 119, 1858-1870. doi: 10.1172/jci37444

Shah, S. H., Kraus, W. E., and Newgard, C. B. (2012). Metabolomic profiling for the identification of novel biomarkers and mechanisms related to common cardiovascular diseases: form and function. Circulation 126, 1110-1120. doi: 10.1161/CIRCULATIONAHA.111.060368

Shen, X., Cheng, S., Peng, Y., Song, H., and Li, H. (2014). Attenuation of early liver fibrosis by herbal compound "Diwu Yanggan" through modulating the balance between epithelial-to-mesenchymal transition and mesenchymal-to-epithelial transition. BMC Complement. Altern. Med. 14:418. doi: 10.1186/1472-6882-14-418

Skaria, S. D., Yang, J., Condos, R., and Smaldone, G. C. (2015). Inhaled interferon and diffusion capacity in Idiopathic Pulmonary Fibrosis (IPF). Sarcoidosis Vasc. Diffuse Lung Dis. 32, 37-42.

Smith, M. R., Gangireddy, S. R., Narala, V. R., Hogaboam, C. M., Standiford, T. J., Christensen, P. J., et al. (2010). Curcumin inhibits fibrosis-related effects in IPF fibroblasts and in mice following bleomycin-induced lung injury. Am. J. Physiol. Lung Cell. Mol. Physiol. 298, L616-L625. doi: 10.1152/ajplung.00002.2009

Stenstrom, M., Nyhlen, H. C., Torngren, M., Liberg, D., Sparre, B., Tuvesson, H., et al. (2016). Paquinimod reduces skin fibrosis in tight skin 1 mice, an experimental model of systemic sclerosis. J. Dermatol. Sci. 83, 52-59. doi: 10.1016/j.jdermsci.2016.04.006

Sun, X., Liu, Y., Li, C., Wang, X., Zhu, R., Liu, C., et al. (2017). Recent advances of curcumin in the prevention and treatment of renal fibrosis. Biomed Res. Int. 2017:2418671. doi: 10.1155/2017/2418671

Tada, S., Iwamoto, H., Nakamuta, M., Sugimoto, R., Enjoji, M., Nakashima, Y., et al. (2001). A selective ROCK inhibitor, Y27632, prevents dimethylnitrosamine-induced hepatic fibrosis in rats. J. Hepatol. 34, 529-536. doi: 10.1016/S0168-8278(00)00059-3

Tajima, S., Bando, M., Yamasawa, H., Ohno, S., Moriyama, H., Terada, M., et al. (2007). Preventive effect of hochu-ekki-to, a Japanese herbal medicine, on bleomycin-induced lung injury in mice. Respirology 12, 814-822. doi: 10.1111/j.1440-1843.2007.01146.x

Takemasa, A., Ishii, Y., and Fukuda, T. (2012). A neutrophil elastase inhibitor prevents bleomycin-induced pulmonary fibrosis in mice. Eur. Respir. J. 40, 1475-1482. doi: 10.1183/09031936.00127011

Tanaka, T., Ogawa, M., Suzuki, J., Sekinishi, A., Itai, A., Hirata, Y., et al. (2012). Inhibition of IkappaB phosphorylation prevents load-induced cardiac dysfunction in mice. Am. J. Physiol. Heart Circ. Physiol. 303, H1435-H1445. doi: 10.1152/ajpheart.00290.2012

Tang, W. W., Ulich, T. R., Lacey, D. L., Hill, D. C., Qi, M., Kaufman, S. A., et al. (1996). Platelet-derived growth factor-BB induces renal tubulointerstitial myofibroblast formation and tubulointerstitial fibrosis. Am. J. Pathol. 148, 1169-1180.

Taniyama, Y., Morishita, R., Aoki, M., Hiraoka, K., Yamasaki, K. Hashiya, N., et al. (2002). Angiogenesis and antifibrotic action by hepatocyte growth factor in cardiomyopathy. Hypertension 40, 47-53. doi: 10.1161/01.hyp.0000020755.56955.bf

Thannickal, V. J., Lee, D. Y., White, E. S., Cui, Z., Larios, J. M., Chacon, R., et al. (2003). Myofibroblast differentiation by transforming growth factor-betal is dependent on cell adhesion and integrin signaling via focal adhesion kinase. J. Biol. Chem. 278, 12384-12389. doi: 10.1074/jbc.M20 8544200

Thum, T., Gross, C., Fiedler, J., Fischer, T., Kissler, S., Bussen, M., et al. (2008). MicroRNA-21 contributes to myocardial disease by stimulating MAP kinase signalling in fibroblasts. Nature 456, 980-984. doi: 10.1038/nature 07511

Traber, P. G., and Zomer, E. (2013). Therapy of experimental NASH and fibrosis with galectin inhibitors. PLOS ONE 8:e83481. doi: 10.1371/journal.pone.0083481

Tsai, J. H., Liu, J. Y., Wu, T. T., Ho, P. C., Huang, C. Y., Shyu, J. C., et al. (2008). Effects of silymarin on the resolution of liver fibrosis induced by carbon tetrachloride in rats. J. Viral Hepat. 15, 508-514. doi: 10.1111/j.1365-2893.2008.00971.x

Tulek, B., Kiyan, E., Toy, H., Kiyici, A., Narin, C., and Suerdem, M. (2011). Anti-inflammatory and anti-fibrotic effects of sirolimus on bleomycin-induced pulmonary fibrosis in rats. Clin. Invest. Med. 34:E341. doi: 10.25011/cim.v34i6.15894

van Dijk, F., Olinga, P., Poelstra, K., and Beljaars, L. (2015). Targeted therapies in liver fibrosis: combining the best parts of platelet-derived growth factor $\mathrm{BB}$ and interferon gamma. Front. Med. 2:72. doi: 10.3389/fmed.2015.00072

Verbeke, L., Mannaerts, I., Schierwagen, R., Govaere, O., Klein, S., Vander Elst, I., et al. (2016). FXR agonist obeticholic acid reduces hepatic inflammation and fibrosis in a rat model of toxic cirrhosis. Sci. Rep. 6:33453. doi: $10.1038 /$ srep33453

Vilaseca, M., Garcia-Caldero, H., Lafoz, E., Ruart, M., Lopez-Sanjurjo, C. I., Murphy, M. P., et al. (2017). Mitochondria-targeted antioxidant mitoquinone deactivates human and rat hepatic stellate cells and reduces portal hypertension in cirrhotic rats. Liver Int. 37, 1002-1012. doi: 10.1111/liv.13436

Vittal, R., Fisher, A., Gu, H., Mickler, E. A., Panitch, A., Lander, C., et al. (2013). Peptide-mediated inhibition of mitogen-activated protein kinase-activated protein kinase-2 ameliorates bleomycin-induced pulmonary fibrosis. Am. J. Respir. Cell Mol. Biol. 49, 47-57. doi: 10.1165/rcmb.20120389OC 
Wang, H., Lafdil, F., Wang, L., Yin, S., Feng, D., and Gao, B. (2011). Tissue inhibitor of metalloproteinase 1 (TIMP-1) deficiency exacerbates carbon tetrachloride-induced liver injury and fibrosis in mice: involvement of hepatocyte STAT3 in TIMP-1 production. Cell Biosci. 1:14. doi: 10.1186/20453701-1-14

Wang, Q., Usinger, W., Nichols, B., Gray, J., Xu, L., Seeley, T. W., et al. (2011). Cooperative interaction of CTGF and TGF-beta in animal models of fibrotic disease. Fibrogenesis Tissue Repair 4:4. doi: 10.1186/17551536-4-4

Wang, W., Zhou, P. H., Xu, C. G., Zhou, X. J., Hu, W., and Zhang, J. (2015). Baicalein attenuates renal fibrosis by inhibiting inflammation via downregulating NF-kappaB and MAPK signal pathways. J. Mol. Histol. 46, 283-290. doi: 10.1007/s10735-015-9621-8

Wang, Y. R., Tian, F. L., Yan, M. X., Fan, J. H., Wang, L. Y., Kuang, R. G., et al. (2016). Sulfasalazine inhibits inflammation and fibrogenesis in pancreas via NF-kappaB signaling pathway in rats with oxidative stress-induced pancreatic injury. Drug Des. Devel. Ther. 10, 1743-1751. doi: 10.2147/DDDT. S107679

Wang, Y., Fan, X., Qu, H., Gao, X., and Cheng, Y. (2012). Strategies and techniques for multi-component drug design from medicinal herbs and traditional Chinese medicine. Curr. Top. Med. Chem. 12, 1356-1362. doi: $10.2174 / 156802612801319034$

Wang, Y., Lin, W., Li, C., Singhal, S., Jain, G., Zhu, L., et al. (2017). Multipronged therapeutic effects of chinese herbal medicine qishenyiqi in the treatment of acute myocardial infarction. Front. Pharmacol. 8:98. doi: 10.3389/fphar.2017.00098

Weingartner, S., Zerr, P., Tomcik, M., Palumbo-Zerr, K., Distler, A., Dees, C., et al. (2012). Pomalidomide is effective for prevention and treatment of experimental skin fibrosis. Ann. Rheum. Dis. 71, 1895-1899. doi: 10.1136/annrheumdis-2012-201784

Wenzke, K. E., Cantemir-Stone, C., Zhang, J., Marsh, C. B., and Huang, K. (2012). Identifying common genes and networks in multi-organ fibrosis. AMIA Jt Summits Transl. Sci. Proc. 2012, 106-115.

Wilkins, B. S., Radia, D., Woodley, C., Farhi, S. E., Keohane, C., and Harrison, C. N. (2013). Resolution of bone marrow fibrosis in a patient receiving JAK1/JAK2 inhibitor treatment with ruxolitinib. Haematologica 98, 1872-1876. doi: 10.3324/haematol.2013.095109

Witek, R. P., Stone, W. C., Karaca, F. G., Syn, W. K., Pereira, T. A., Agboola, K. M., et al. (2009). Pan-caspase inhibitor VX-166 reduces fibrosis in an animal model of nonalcoholic steatohepatitis. Hepatology 50, 1421-1430. doi: 10.1002/hep. 23167

Wong, M. G., Panchapakesan, U., Qi, W., Silva, D. G., Chen, X. M., and Pollock, C. A. (2011). Cation-independent mannose 6-phosphate receptor inhibitor (PXS25) inhibits fibrosis in human proximal tubular cells by inhibiting conversion of latent to active TGF-beta1. Am. J. Physiol. Renal Physiol. 301, F84-F93. doi: 10.1152/ajprenal.00287.2010

Wynn, T. A. (2008). Cellular and molecular mechanisms of fibrosis. J. Pathol. 214, 199-210. doi: 10.1002/path.2277

Xu, L., Yates, C. C., Lockyer, P., Xie, L., Bevilacqua, A., He, J., et al. (2014). MMI0100 inhibits cardiac fibrosis in myocardial infarction by direct actions on cardiomyocytes and fibroblasts via MK2 inhibition. J. Mol. Cell. Cardiol. 77, 86-101. doi: 10.1016/j.yjmcc.2014.09.011

Xu, L., Yin, L., Tao, X., Qi, Y., Han, X., Xu, Y., et al. (2017). Dioscin, a potent ITGA5 inhibitor, reduces the synthesis of collagen against liver fibrosis: Insights from SILAC-based proteomics analysis. Food Chem. Toxicol. 107(Pt A), 318-328. doi: 10.1016/j.fct.2017.07.014

Yang, C. Q., Sun, P. Y., Ding, D. Z., Moriuchi, H., Ishitsuka, Y., Irikura, M., et al. (2010). The ethical Kampo formulation Sho-seiryu-to (TJ-19) prevents bleomycin-induced pulmonary fibrosis in rats. Biol. Pharm. Bull. 33, 1438-1442. doi: 10.1248/bpb.33.1438

Yang, J., Cui, Y., and Kolb, M. (2009). How useful is traditional herbal medicine for pulmonary fibrosis? Respirology 14, 1082-1091. doi: 10.1111/j.1440-1843.2009.01644.x

Yang, J., Savvatis, K., Kang, J. S., Fan, P., Zhong, H., Schwartz, K., et al. (2016). Targeting LOXL2 for cardiac interstitial fibrosis and heart failure treatment. Nat. Commun. 7:13710. doi: 10.1038/ncomms 13710

Yang, L., Chan, C. C., Kwon, O. S., Liu, S., McGhee, J., Stimpson, S. A., et al. (2006). Regulation of peroxisome proliferator-activated receptor-gamma in liver fibrosis. Am. J. Physiol. Gastrointest. Liver Physiol. 291, G902-G911. doi: 10.1152/ajpgi.00124.2006

Yao, X. X., Jiang, S. L., Tang, Y. W., Yao, D. M., and Yao, X. (2005). Efficacy of Chinese medicine Yi-gan-kang granule in prophylaxis and treatment of liver fibrosis in rats. World J. Gastroenterol. 11, 2583-2590. doi: 10.3748/wjg.v11.i17.2583

Yen, F. L., Wu, T. H., Liao, C. W., and Lin, C. C. (2007). A kampo medicine, YinChiao-san, prevents bleomycin-induced pulmonary injury in rats. Phytother. Res. 21, 251-258. doi: 10.1002/ptr.2056

Yin, L., Qi, Y., Xu, Y., Xu, L., Han, X., Tao, X., et al. (2017). Dioscin inhibits HSC-T6 cell migration via adjusting SDC-4 expression: insights from iTRAQ-based quantitative proteomics. Front. Pharmacol. 8:665. doi: 10.3389/fphar.2017.00665

Zeybel, M., Hardy, T., Robinson, S. M., Fox, C., Anstee, Q. M., Ness, T., et al. (2015). Differential DNA methylation of genes involved in fibrosis progression in non-alcoholic fatty liver disease and alcoholic liver disease. Clin. Epigenetics 7:25. doi: 10.1186/s13148-015-0056-6

Zhang, H. Q., Yau, Y. F., Wong, M. S., Man, O. Y., He, Y. Y., Chan, N. et al. (2008). Chinese medicine formula DSQRL versus glucocorticoids for the treatment of experimental pulmonary fibrosis. J. Ethnopharmacol. 116, 318-324. doi: 10.1016/j.jep.2007.11.039

Zhang, L., Fu, X. H., Yu, Y., Shui, R. H., Li, C., Zeng, H. Y., et al. (2015). Treatment with CA-074Me, a Cathepsin B inhibitor, reduces lung interstitial inflammation and fibrosis in a rat model of polymyositis. Lab. Invest. 95, 65-77. doi: 10.1038/labinvest.2014.135

Zhang, L., He, Y. L., Li, Q. Z., Hao, X. H., Zhang, Z. F., Yuan, J. X., et al. (2014). Nacetylcysteine alleviated silica-induced lung fibrosis in rats by down-regulation of ROS and mitochondrial apoptosis signaling. Toxicol. Mech. Methods 24, 212-219. doi: 10.3109/15376516.2013.879974

Zhang, S., Wang, J., Liu, Q., and Harnish, D. C. (2009). Farnesoid X receptor agonist WAY-362450 attenuates liver inflammation and fibrosis in murine model of non-alcoholic steatohepatitis. J. Hepatol. 51, 380-388. doi: 10.1016/j.jhep.2009.03.025

Zhang, X., Han, X., Yin, L., Xu, L., Qi, Y., Xu, Y., et al. (2015a). Potent effects of dioscin against liver fibrosis. Sci. Rep. 5:9713. doi: 10.1038/srep 09713

Zhang, X., Xu, L., Yin, L., Qi, Y., Xu, Y., Han, X., et al. (2015b). Quantitative chemical proteomics for investigating the biomarkers of dioscin against liver fibrosis caused by CCl4 in rats. Chem. Commun. 51, 11064-11067. doi: $10.1039 / \mathrm{c} 4 \mathrm{cc} 09160 \mathrm{~d}$

Zhang, X., Yan, C., Hang, J., Finci, L. I., Lei, J., and Shi, Y. (2017). An atomic structure of the human spliceosome. Cell 169, 918 e914-929 e914. doi: 10.1016/j.cell.2017.04.033

Zhang, Y. E. (2009). Non-Smad pathways in TGF-beta signaling. Cell Res. 19, 128-139. doi: 10.1038/cr.2008.328

Zhang, Y., Edgley, A. J., Cox, A. J., Powell, A. K., Wang, B., Kompa, A. R., et al. (2012). FT011, a new anti-fibrotic drug, attenuates fibrosis and chronic heart failure in experimental diabetic cardiomyopathy. Eur. J. Heart Fail. 14, 549-562. doi: 10.1093/eurihf/hfs011

Zhang, Z., Guo, Y., Zhang, S., Zhang, Y., Wang, Y., Ni, W., et al. (2013) Curcumin modulates cannabinoid receptors in liver fibrosis in vivo and inhibits extracellular matrix expression in hepatic stellate cells by suppressing cannabinoid receptor type-1 in vitro. Eur. J. Pharmacol. 721, 133-140. doi: 10.1016/j.ejphar.2013.09.042

Zhao, H., Chan-Li, Y., Collins, S. L., Zhang, Y., Hallowell, R. W., Mitzner, W., et al. (2014). Pulmonary delivery of docosahexaenoic acid mitigates bleomycin-induced pulmonary fibrosis. BMC Pulm. Med. 14:64. doi: 10.1186/1471-2466-14-64

Zhao, X. K., Yu, L., Cheng, M. L., Che, P., Lu, Y. Y., Zhang, Q., et al. (2017). Focal adhesion kinase regulates hepatic stellate cell activation and liver fibrosis. Sci. Rep. 7:4032. doi: 10.1038/s41598-017-04317-0

Zheng, H., Handing, K. B., Zimmerman, M. D., Shabalin, I. G., Almo, S. C., and Minor, W. (2015). X-ray crystallography over the past decade for novel drug discovery - where are we heading next? Expert Opin. Drug Discov. 10, 975-989. doi: 10.1517/17460441.2015.1061991

Zhou, X. M., Zhang, G. C., Li, J. X., and Hou, J. (2007). Inhibitory effects of Hu-qiyin on the bleomycin-induced pulmonary fibrosis in rats. J. Ethnopharmacol. 111, 255-264. doi: 10.1016/j.jep.2006.11.029 
Zhou, Y. N., Sun, M. Y., Mu, Y. P., Yang, T., Ning, B. B., Ren, S., et al. (2014). Xuefuzhuyu decoction inhibition of angiogenesis attenuates liver fibrosis induced by $\mathrm{CCl}(4)$ in mice. J. Ethnopharmacol. 153, 659-666. doi: 10.1016/j.jep.2014.03.019

Zhou, Y. X., Qiu, Y. Q., Xu, L. Q., Guo, J., and Li, L. J. (2012). Xiao-Chai-Hu Tang in treating model mice with D-galactosamine-induced liver injury. Afr. J. Tradit. Complement. Altern. Med. 9, 405-411. doi: 10.4314/ajtcam.v9i3.16

Zhu, X. Y., Chade, A. R., Krier, J. D., Daghini, E., Lavi, R., Guglielmotti, A., et al. (2009). The chemokine monocyte chemoattractant protein-1 contributes to renal dysfunction in swine renovascular hypertension. J. Hypertens. 27, 2063-2073. doi: 10.1097/HJH.0b013e32833 00192
Conflict of Interest Statement: The authors declare that the research was conducted in the absence of any commercial or financial relationships that could be construed as a potential conflict of interest.

The reviewer XT and handling Editor declared their shared affiliation.

Copyright (c) $2017 \mathrm{Li}, \mathrm{Zhu}$, Wang, Yuan and Zhu. This is an open-access article distributed under the terms of the Creative Commons Attribution License (CC BY). The use, distribution or reproduction in other forums is permitted, provided the original author(s) or licensor are credited and that the original publication in this journal is cited, in accordance with accepted academic practice. No use, distribution or reproduction is permitted which does not comply with these terms. 